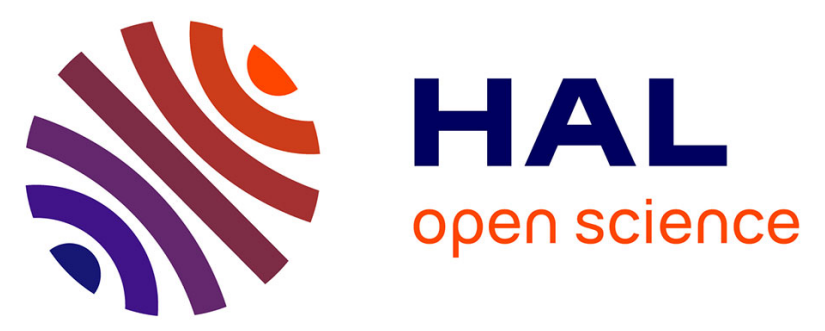

\title{
Perinatal adversity profiles and suicide attempt in adolescence and young adulthood: longitudinal analyses from two 20-year birth cohort studies
}

Massimiliano Orri, Abigail E Russell, Becky Mars, Gustavo Turecki, David Gunnell, Jon Heron, Richard E Tremblay, Michel Boivin, Anne-Monique Nuyt, Sylvana Côté, et al.

\section{To cite this version:}

Massimiliano Orri, Abigail E Russell, Becky Mars, Gustavo Turecki, David Gunnell, et al.. Perinatal adversity profiles and suicide attempt in adolescence and young adulthood: longitudinal analyses from two 20-year birth cohort studies. Psychological Medicine, In press, 10.1017/S0033291720002974 . hal-02958893

\section{HAL Id: hal-02958893 \\ https://hal.science/hal-02958893}

Submitted on 6 Oct 2020

HAL is a multi-disciplinary open access archive for the deposit and dissemination of scientific research documents, whether they are published or not. The documents may come from teaching and research institutions in France or abroad, or from public or private research centers.
L'archive ouverte pluridisciplinaire HAL, est destinée au dépôt et à la diffusion de documents scientifiques de niveau recherche, publiés ou non, émanant des établissements d'enseignement et de recherche français ou étrangers, des laboratoires publics ou privés. 
Title: Perinatal adversity profiles and suicide attempt in adolescence and young adulthood: Longitudinal analyses from two 20-year birth cohort studies

Authors: Massimiliano Orri, $\mathrm{PhD}^{1,2}$; Abigail E. Russell, $\mathrm{PhD}^{3,4}$; Becky Mars, $\mathrm{PhD}^{3,4}$; Gustavo Turecki, $\mathrm{MD}, \mathrm{PhD}^{1}$; David Gunnell, DSci ${ }^{3,4}$; Jon Heron, $\mathrm{PhD}^{3}$; Richard E. Tremblay, $\mathrm{PhD}^{5,6}$; Michel Boivin, $\mathrm{PhD}^{7}$; Anne-Monique Nuyt, $\mathrm{MD}^{8}$; Sylvana M. Côté, $\mathrm{PhD}^{9}$; Marie-Claude Geoffroy, $\mathrm{PhD}^{10}$

\author{
Affiliations: \\ ${ }^{1}$ McGill Group for Suicide Studies, Douglas Mental Health University Institute, Department of Psychiatry, McGill \\ University, Montreal, QC, Canada \\ ${ }^{2}$ Bordeaux Population Health Research Centre, Inserm U1219, University of Bordeaux, Bordeaux, France \\ ${ }^{3}$ Centre for Academic Mental Health, Population Health Sciences, University of Bristol Medical School, Bristol, UK \\ (Russell, Mars, Gunnell, Heron); \\ ${ }^{4}$ National Institute of Health Research Biomedical Research Centre, University Hospitals Bristol NHS Foundation Trust, \\ University of Bristol, Bristol, UK (Mars, Gunnell) \\ ${ }^{5}$ School of Public Health, Physiotherapy and Sports Science, University College Dublin, Dublin, Ireland (Tremblay) \\ ${ }^{6}$ Departments of Pediatrics and Psychology, University of Montréal, Montreal, QC, Canada (Tremblay) \\ ${ }^{7}$ School of Psychology, Université Laval, Québec City, Québec, Canada (Boivin) \\ ${ }^{8}$ Centre Hospitalier Universitaire Sainte-Justine Research Center, Department of Pediatrics, University of Montreal, \\ Montreal, QC, Canada (Nuyt) \\ ${ }^{9}$ Department of Social and Preventive Medicine, University of Montreal, Montreal, QC, Canada (Côté); \\ ${ }^{10}$ Department of Educational and Counselling Psychology, McGill University, Montreal, QC, Canada (Geoffroy)
}

Corresponding author: Marie-Claude Geoffroy, McGill Group for Suicide Studies, Douglas Mental Health University Institute, McGill University, 6875 LaSalle Boulevard, Montreal, Quebec H4H 1R3.

Phone: +1-514-761-6131

Email: marie-claude.geoffroy@mcgill.ca

Word count: 3906 


\begin{abstract}
Background. We aimed to identify groups of children presenting distinct perinatal adversity profiles and test the association between profiles and later risk of suicide attempt.

Methods. Data were from the Québec Longitudinal Study of Child Development (QLSCD, N=1623), and the Avon Longitudinal Study of Parents and Children (ALSPAC, N=5734). Exposures to 32 perinatal adversities (eg, fetal, obstetric, psychosocial, and parental psychopathology) were modeled using latent class analysis, and associations with self-reported suicide attempt by age 20 were investigated with logistic regression. We investigated to what extent childhood emotional and behavioral problems, victimization, and cognition explained the associations.

Results. In both cohorts, we identified 5 profiles: No perinatal risk, Poor fetal growth, Socioeconomic adversity, Delivery complications, Parental mental health problems (ALSPAC only). Compared to children with No perinatal risk, children in the Poor fetal growth (pooled estimate QLSCD-ALSPAC, OR=1.89, 95\%CI=1.04-3.44), Socioeconomic adversity (pooled-OR=1.42, 95\%CI=1.08-1.85), and Parental mental health problems $(\mathrm{OR}=1.74$, $95 \% \mathrm{CI}=1.27-2.40$ ), but not Delivery complications, profiles were more likely to attempt suicide. The proportion of this effect mediated by the putative mediators was larger for the Socioeconomic adversity profile compared to the others.

Conclusions. Perinatal adversities associated with suicide attempt cluster in distinct profiles. Suicide prevention may begin early in life and requires a multidisciplinary approach targeting a constellation of factors from different domains (psychiatric, obstetric, socioeconomic), rather than a single factor, to effectively reduce suicide vulnerability. The way these factors cluster together also determined the pathways leading to suicide attempt, which can guide decisionmaking on personalized suicide prevention strategies.
\end{abstract}

Keywords: suicide attempt, perinatal adversity, latent class analysis, ALSPAC, QLSCD 


\section{Introduction}

Suicide attempt in adolescence and young adulthood is an important public health problem, with rates ranging from $3.1 \%$ to $8.8 \%$ in community samples of youth aged 15-25 years (Cha et al., 2018; Nock et al., 2008, 2013; Orri et al., 2020). Suicide attempt is associated with important health and social consequences, such as increased risk of suicide mortality (second leading cause of death in 15-24 year-olds), poor mental and physical health, and negative social outcomes (Bostwick, Pabbati, Geske, \& McKean, 2016; Goldman-Mellor et al., 2014; Hawton \& O’Connor, 2012; Reinherz, Tanner, Berger, Beardslee, \& Fitzmaurice, 2006). Early identification of individuals at risk for suicidal behavior is critical in order to implement timely preventive interventions.

Despite risk factors such as exposure to violence (Geoffroy et al., 2018, 2016; Geoffroy, Orri, Girard, Perret, \& Turecki, 2020), drug abuse (Gobbi et al., 2019), and psychopathology (Arsenault-Lapierre, Kim, \& Turecki, 2004; Orri, Galera, et al., 2018; Orri, Perret, Turecki, \& Geoffroy, 2018; Orri et al., 2020; Turecki, 2005) being important proximal predictors of adolescent suicidal behaviors, past studies including a recent meta-analysis suggested that exposure to adversities during the perinatal period may also substantially contribute to increased susceptibility to suicidal behavior later in life (Geoffroy, Gunnell, \& Power, 2014; O’Donnell \& Meaney, 2016; Orri et al., 2019; Turecki \& Brent, 2016). For example, evidence showed that perinatal factors such as poor fetal growth (e.g., low birth weight), adverse socioeconomic environment (e.g., low socioeconomic status), family characteristics (e.g., nonintact family), and exposure to alcohol/drugs during pregnancy are associated with suicide risk in both adolescence and adulthood (Cnattingius, Svensson, Granath, \& Iliadou, 2011; D’Onofrio et al., 2013, 2014; Geoffroy et al., 2014; Mittendorfer-Rutz, Rasmussen, \& Wasserman, 2004; Orri et al., 2019). Documenting the association between such perinatal factors and suicide attempt may help with the early identification of children more at risk of suicide later in life (Aizer \& Currie, 2014; Gunnell, 2015).

Current knowledge of associations between perinatal factors and suicide-related outcomes has several gaps. First, previous studies showing associations between perinatal adversity and suicide risk have focused on one or few factors (Orri et al., 2019), and a comprehensive study assessing a range of fetal, psychosocial, obstetric, and parental health factors is lacking. Second, previous studies have not considered the co-occurrence of such perinatal factors within the same individual. For example, low birth weight is more common in infants from impoverished backgrounds, mothers who smoked during pregnancy, suffer from depression (Grote et al., 2010) and have low education (Aizer \& Currie, 2014; Parker, Schoendorf, \& Kiely, 1994). By relying on statistical models such as multiple regression, previous studies documented independent associations of a limited range of perinatal factors with 
suicidal behavior (e.g., the effect of birth weight on suicidal behavior as if all mothers have equal levels of depression, education, smoking (D’Onofrio et al., 2013, 2014; Mittendorfer-Rutz et al., 2004)), but did not capture the cooccurrence of multiple risk factors among the same individual (e.g., accounting for the fact that mothers having low birth weight children are also more likely to experience depression, low education, and to smoke). Third, perinatal factors are also associated with later emotional (e.g., depression (Gale \& Martyn, 2004)), behavioral (e.g., hyperactivity-impulsivity (Class, Rickert, Larsson, Lichtenstein, \& D’Onofrio, 2014; Lim et al., 2018), and conduct problems (Mathewson et al., 2017)), interpersonal (e.g., peer victimization), and cognitive problems (FlensborgMadsen \& Mortensen, 2017). As these problems are also independent risk factors for suicidal behaviors (Geoffroy et al., 2016; Richard-Devantoy et al., 2019; Turecki \& Brent, 2016), the association between perinatal adversity and suicidal behavior reported in previous studies is likely to be explained, at least partially, by such factors (Orri et al., 2019). Therefore, studies are needed to clarify whether the association of perinatal factors with suicidal behavior is mediated by more proximal childhood factors.

This study aimed to 1) identify clusters of children presenting distinct risk profiles of perinatal adversity (including fetal, obstetric, psychosocial, parental mental health problems and substance use); 2) test the association between identified perinatal adversity profiles and suicide attempt by early adulthood; 3 ) determine if perinatal adversity profiles are independently associated with suicide attempt, or whether the association is explained by childhood emotional, behavioral, interpersonal, and cognitive problems that are a consequence of perinatal adversity. We utilized data from 2 independent birth cohorts to provide replication of our findings.

\section{Methods}

\section{Participants and data}

Data were from the Québec Longitudinal Study of Child Development (QLSCD) in Québec, Canada, and the Avon Longitudinal Study of Parents and Children (ALSPAC) in the UK. QLSCD (which is conducted by the Institut de la statistique du Québec, ISQ) is an ongoing birth cohort initially including 2120 singletons born in 1997/98 to mothers living in the Canadian Province of Québec (http://www.jesuisjeserai.stat.gouv.qc.ca/default an.htm). Participants were selected from birth registers following a random procedure based on living areas and birth rates. The target population represents $94.5 \%$ of the Québec population of singleton births, including all ranges of socioeconomic status. Families were included if pregnancy lasted 24-42 weeks and if the mother could speak French or English. The QLSCD protocol was approved by the ISQ and the St-Justine Hospital Research Centre ethics committees, and 
informed consent was obtained at each assessment. ALSPAC is an ongoing birth cohort: pregnant women resident in Avon, UK, with expected dates of delivery 1st April 1991 to 31st December 1992 were invited to participate. The cohort initially included 14,062 live births and 13,988 children who were alive at 1 year of age. More were added in a later data collection, for a total of 15,589 live births (14,901 children alive at one year of age)(Boyd et al., 2013; Fraser et al., 2013; Northstone et al., 2019). Ethical approval for the study was obtained from the ALSPAC Law and Ethics committee and local research ethics committees, and informed consent was obtained from participating families. Informed consent for the use of data collected via questionnaires and clinics was obtained from participants following the recommendations of the ALSPAC Ethics and Law Committee at the time. Please note that the study website contains details of all the data that is available through a fully searchable data dictionary and variable search tool (http://www.bristol.ac.uk/alspac/researchers/our-data/). One of each twin pair was excluded at random for the current analysis, and it should be noted that only a subsample of ALSPAC $(n=8369)$ had data from obstetric records extracted due to funding restrictions (detail available from authors on request).

All participants were followed-up until early adulthood (i.e., 20 years for QLSCD and 21 years for ALSPAC) with repeated assessments from parents/teachers/self-reports and linkage with hospital records.

We included 1623 participants from QLSCD (845, 52.1\% females; representing 77\% of the original sample) and 5765 participants from ALSPAC (3356, 58.2\% females; representing 41\% of the original sample) with information on suicide attempt. Included participants differed from non-included on some characteristics, such as being more likely to be female, and having parents with higher socioeconomic status (see Table S1). To reduce the influence of differential attrition on our analyses, we used inverse probability weighting, in which weights represent the probability of inclusion in the sample estimated from characteristics independently predicting missingness. Missing data on prenatal and perinatal variables (Table S1) were handled using Full Information Maximum Likelihood.

\section{Suicide attempt by early adulthood}

Suicide attempt (i.e., self-harm with intent to die) was assessed via self-report questions at 13, 15, 17 and 20 years in QLSCD and at 16 and 21 years in ALSPAC. In QLSCD, adolescents endorsing serious thought of attempting suicide were asked: "in the past 12 months: how many times did you attempt suicide?" ( 0 vs $\geq 1)$. At age 20 , lifetime suicide attempt was also assessed through the questions: "Did you ever go to the emergency department for a suicide attempt", and "Have you ever been hospitalized for a suicide attempt". In ALSPAC, adolescents reporting self-harm, i.e., positive answer to the question: "Have you ever hurt yourself on purpose in any way (e.g., by taking an overdose 
of pills or by cutting yourself)?" were asked: "On any of the occasions when you have hurt yourself on purpose, have you ever seriously wanted to kill yourself?", and "wanted to die" to assess intentionality. In both cohorts, if a participant endorsed any of the suicide attempt questions or manifested intent to die at any time point, they were coded as positive for our outcome.

\section{Perinatal adversity}

We assessed 32 perinatal adversity factors, including adversities related to fetal growth, socioeconomic status, exposure to substances during pregnancy, and exposure to parental mental health problems. These variables are detailed in Table 1.

\section{Mediators}

In both cohorts, we used teacher ratings of emotional and behavioral problems, self-reports of peer victimization, and standardized assessments of cognitive skills. Emotional (i.e., anxiety/depressive symptoms) and behavioral (i.e., conduct and hyperactive-impulsive) problems were assessed with the Social Behavior Questionnaire (Murray, Eisner, \& Ribeaud, 2017) in QLSCD at ages 6, 7, 8, 10, and 12, and with the Strengths and Difficulties Questionnaire (Goodman, 1997) in ALSPAC at ages 7/8, and 10/11. Peer victimization was assessed with a modified version of the Self-report victimization scale (Ladd \& Kochenderfer-Ladd, 2002) in QLSCD at ages 6, 7, 8, 10, and 12, and with a modified version of the Bullying and Friendship Interview Schedule (Wolke, Woods, Bloomfield, \& Karstadt, 2000) in ALSPAC at ages 8 and 10. Cognitive skills (i.e., verbal intelligence) were measured using the Peabody Picture Vocabulary Test (Dunn, Thériault-Whalen, \& Dunn, 1993) in QLSCD at age 4, 7, and 10, and with the Wechsler Preschool \& Primary Scale of Intelligence and the Wechsler Intelligence Scale for Children (Wechsler, 1949) in ALSPAC at ages 4 and 8, respectively. Each measure was averaged across the available data points. We provided details on each measure in Table $\mathbf{S 2}$.

\section{Statistical analysis}

Analyses were conducted in QLSCD, and subsequently replicated in ASLPAC. Models were estimated using Mplus version 7.3 and 8 (Muthén \& Muthén, 1998-2017) with Maximum Likelihood and robust (Huber-White) standard errors.

Descriptive statistics and associations. Prevalence of each perinatal adversity was estimated for each cohort. Then, we described the association between each perinatal adversity and suicide attempt from sex-adjusted binary logistic regression. This was estimated in both cohorts separately, then estimates were pooled using inverse-variance weighted meta-analysis. 
Identifying perinatal adversity profiles. We used Latent Class Analysis to identify homogeneous groups of children having distinct patterns of exposure to the 32 perinatal adversity factors (Lanza \& Rhoades, 2013; Orri et al., 2017). Latent Class Analysis models with 1 to 6 latent classes were sequentially fitted, and the optimal number of classes was chosen considering established fit indices (Bayesian Information Criterion, Vuong-Lo-Mendel-Rubin Likelihood Ratio Test), the proportion of participants in each class, and the interpretability of the model. Entropy, indicating the accuracy with which models classify individuals into their most likely class (range $0-1$, higher values indicating better classification accuracy) was also considered. After the selection of the best model in each sample, individuals were assigned to a latent class according to their highest posterior probability.

Association of perinatal adversity profiles with suicide attempt. We used binary logistic regression (adjusted for sex) to estimate the association between the identified perinatal adversity profiles and later suicide attempt (total effect). No sex-by-profile interaction was found.

Mediation analysis. We conducted mediation analysis in Mplus using the product of coefficients method for the perinatal profiles showing evidence of total association with suicide attempt. We calculated the indirect (i.e., association between perinatal adversity profiles and suicide attempt through mediators) and direct effects (i.e., association between perinatal adversity profiles and suicide attempt independent from -not explained by- the mediators). Additionally, we calculated the proportion of the association that was mediated using the ratio between indirect and total effects. Models with all mediators entered simultaneously and models with each individual mediator were estimated.

Estimating pooled effect sizes. For all models, associations were estimated for each cohort, then the estimates were pooled using inverse-variance weighted meta-analysis.

\section{Results}

\section{Prevalence of suicide attempt}

The prevalence of suicide attempt was similar in both QLSCD (134 of 1623, 8.3\%) and ALSPAC (484 of 5765, 8.4\%). In both cohorts, girls were more likely to report suicide attempt than boys (QLSCD: girls, $\mathrm{n}=91$ of $845,10.8 \%$; boys, $\mathrm{n}=43$ of $778,5.5 \%$; $P<0.001$; ALSPAC: girls, $\mathrm{n}=383$ of $3356,11.4 \%$; boys, $\mathrm{n}=101$ of $2406,4.2 \%$; $P<0.001$ ).

\section{Prevalence of perinatal adversities and association with suicide attempt}

Most perinatal adversities were similarly prevalent in the two cohorts, with several exceptions (e.g., short birth length, long hospitalization; see Table 2). Associations of each perinatal adversity with suicide attempt are reported in Table 
2. Evidence of association with suicide attempt was found for low birth weight (OR, 1.52; 95\%CI,1.05-2.20), low socioeconomic status (OR, 1.64; 95\%CI, 1.29-2.08), nonintact family (OR, 1.93; 95\%CI, 1.51-2.47), low maternal age (OR, 1.87; 95\%CI, 1.16-3.02), exposure to smoking during pregnancy (OR, 1.94; 95\%CI, 1.62-2.32), maternal depression (OR, 1.64; 95\%CI, 1.27-2.12) and anxiety (OR, 1.64; 95\%CI, 1.27-2.12), and paternal antisocial behavior $(\mathrm{OR}, 1.93 ; 95 \% \mathrm{CI}, 1.32-2.84)$ when estimates from both cohorts were pooled.

\section{Perinatal adversity profiles}

We identified the following perinatal profiles (Figure 1): Poor fetal growth ( $\mathrm{n}=75,4.6 \%$ in QLSCD; $\mathrm{n}=298,5.2 \%$ in ALSPAC), including children with the highest probabilities of showing fetal growth adversity, but also showing high probability of other adversity such as birth/delivery adversity, psychosocial adversity and to be exposed to maternal smoking in pregnancy, and having mothers showing depression; Socioeconomic adversity ( $\mathrm{n}=351,21.6 \%$ in QLSCD; $\mathrm{n}=946,16.5 \%$ in ALSPAC), including children with the highest probabilities of being born in a socioeconomically disadvantaged milieu, exposures to smoking, drugs, alcohol, and medications during pregnancy, and, in QLSCD only, parents with antisocial behaviors and high depressive symptoms; Delivery complications $(\mathrm{n}=397,24.5 \%$ in QLSCD; $\mathrm{n}=591,16.6 \%$ in ALSPAC), including children born with caesarean section and having longer neonatal hospitalization; Parental mental health problems ( $\mathrm{n}=448,7.8 \%$ in ALSPAC only), including children with parents having high rates of anxiety and depressive symptoms. The remaining children were part of the No perinatal risk profile ( $n=801,49.5 \%$ in QLSCD; $n=3091,53.9 \%$ in ALSPAC), including children with average probability of all perinatal adversity factors. Difference in the prevalence of the 32 perinatal adversities in each profile compared to the reference profile (i.e., No perinatal risk) is reported in Figure 2. The proportion of girls and boys within the identified profiles was similar in QLSCD $(P=0.877)$ but varied in ALSPAC $(P<0.001)$ with a somewhat higher proportion of boys in the delivery complications profile than other profiles ( $47 \%$ vs $\leq 42 \%$ for other profiles).

\section{Association of perinatal adversity profiles with suicide attempt}

Prevalence of suicide attempt by profile, in QLSCD and ALSPAC respectively, was 14.9\% (11 of 74) and 11.1\% (33 of 298) in the Poor fetal growth profile, 10.5\% (37 of 351) and 10.2\% (96 of 946) in the Socioeconomic adversity profile, $7.6 \%$ (30 of 397) and 6.5\% (62 of 951) in the Delivery complications profile, $12.5 \%$ (56 of 448$)$ in the Parental mental health problems profile, and 7.0\% (56 of 801) and 7.7\% (237 of 3091) in the No perinatal risk profile (Figure S1).

Sex-adjusted logistic regression showed that children in the Poor fetal growth profile were more likely to attempt suicide by early adulthood than children in the Low perinatal adversity profile, with pooled OR across 
QLSCD and ALSPAC of 1.89; 95\%CI, 1.04-3.44 (cohort specific ORs were QLSCD: 2.84; 95\%CI, 1.32-6.10,

ALSPAC: $1.51 ; 95 \%$ CI, 1.02-2.23). Children in the Socioeconomic adversity (pooled OR, 1.42; 95\%CI, 1.08-1.85;

QLSCD: OR, 1.76; 95\%CI, 1.10-2.81; ALSPAC: OR, 1.30; 95\%CI, 1.01-1.67) and in the Parental mental health problems (ALSPAC only: OR, 1.74; 95\%CI, 1.27-2.40) profiles also had increased risk of suicide attempt by early adulthood, compared with children in the No perinatal risk profile. Finally, children in the Delivery complications profile did not show increased risk of later suicide attempt (pooled: OR, 0.92, 0.71-1.86; QLSCD: 1.06, 0.64-1.75; ALSPAC: $0.87,0.65-1.18$ ) compared with children in the No perinatal risk profile.

\section{Direct and indirect association between perinatal adversity profiles and suicide attempt}

Mediation analysis investigated the proportion of increased risk of attempting suicide for children in the Poor fetal growth, Socioeconomic adversity, and Parental mental health problems profiles that were explained by our putative mediators. For the Poor fetal growth profile, we found that the putative mediators explained $15.0 \%$ of the association (13.7\% in QLSCD and 19.6\% in ALSPAC), with a pooled OR for the indirect effect of 1.10 (95\%CI, 1.04-1.16; see

Table 3 for cohort-specific and mediator-specific direct and indirect effects). Similar results were observed for the Parental mental health problems profiles, with mediators explaining $13.6 \%$ of the association (indirect effect OR, 1.08; 95\%CI, 1.03-1.13). However, for the Socioeconomic adversity profile, the investigated mediators explained a larger portion of association (39.9\% in pooled analysis, $37.1 \%$ in each cohort), with an OR for the indirect effect of 1.15; 95\%CI, 1.03-1.28. Results were consistent for each mediator analyzed singularly, with hyperactivity/impulsivity appearing as the key mediator in all analyses.

\section{Discussion}

To our knowledge, this is the first study identifying distinct profiles of exposure to a range of perinatal adversities and elucidating pathways leading to suicide attempt by early adulthood. Using 2 large independent population samples, we identified 5 profiles of perinatal adversity, which were similar in the 2 samples in terms of nature of adversity, population prevalence, and association with suicide attempt. The similarity of findings in the 2 cohorts, coming from 2 different continents, gives confidence that findings were not sample specific. However, despite the aforementioned similarity, we also found some differences, most of which related to delivery complications rates. For example, prevalence of long hospitalization was higher in ALSPAC compared to QLSCD for each profile (especially in the Delivery complication and Socioeconomic adversity profiles). This may be related to differences in the healthcare system and medical protocols, as well as to measurement differences and the differential extraction of obstetric data 
for a selected subsample of mothers in ALSPAC. A profile clustering children exposed to parental mental health problems was identified only in ALSPAC. In this cohort, the larger sample size (Nylund, Asparouhov, \& Muthén, 2007), the presence of parental anxiety measures (not assessed in QLSCD), and the assessment of maternal depression closer in time with childbirth compared to QLSCD (postnatal depression prevalence declines sharply over time)(Vliegen, Casalin, \& Luyten, 2014) may explain why this profile was not identified in QLSCD.

Our profiles were mainly characterized by high rates of a specific group of perinatal adversities (e.g., fetal growth adversities for children in the Poor fetal growth profile). However, some profiles also presented higher rates of adversities pertaining to other adversity groups, compared with the No perinatal risk profile. For example, children in the Poor fetal growth profile also had higher rates of long hospitalization and birth induction (although lower than for children in the Delivery complications profile), low parental education and SES (although lower than for children in the Socioeconomic adversity profile), and maternal smoking in pregnancy (similar to children in the Socioeconomic adversity profile). This finding indicates that perinatal adversities tend to cluster not only within each group (e.g., several fetal adversities cluster together) but also across groups (e.g., fetal and psychosocial adversities cluster together), as previous studies suggested (Aizer \& Currie, 2014; Grote et al., 2010; Parker et al., 1994).

We found increased risk of suicide attempt for children who had poor fetal growth. This finding is in line with a previous meta-analysis (Orri et al., 2019) showing higher risk of suicide, suicide attempt, and suicidal ideation among children with low birth weight. However, while this meta-analysis did not find associations for other factors such as prematurity, premature children were overrepresented in our Poor fetal growth profile. This finding, which originates from the utilization of a person-centered approach (i.e., LCA) as opposed to a variable-centered approach (i.e., regression), indicates that a given factor may not be a risk factor in the population as a whole, but can be so for a specific subgroup of children presenting with a cluster of adversities (e.g., low birth weight, prematurity, as well as socioeconomic adversities and exposure to smoking in pregnancy). This is especially evident for delivery complication adversities: caesarean section, which have similar prevalence in the Poor fetal growth and Delivery complications profiles, may be a marker of suicide risk only for children presenting with all associated adversities characterizing the Poor fetal growth profile. This finding calls for a multidisciplinary approach in the assessment of perinatal risk factors, in which information from multiple domains (obstetric, psychopathology, early fetal growth, socioeconomic) needs to be considered jointly to estimate the individual risk of later suicide attempt.

In line with previous studies showing negative effects of deprived socioeconomic environments on mental health and suicide risk (Orri et al., 2019; Poulton et al., 2002), we found that children in the Socioeconomic adversity 
profile were at higher risk of suicide attempt. Individual socioeconomic adversities were also those who showed the most consistent associations across the 2 cohorts at the population level (i.e., not considering profiles). It is worth noting that maternal and paternal socioeconomic adversity were similarly overrepresented in this profile, in line with evidence on assortative mating (Nordsletten et al., 2016).

This study also provides insights into mechanisms leading to increased suicide risk for children in the Poor fetal growth, Socioeconomic adversity and Parental mental health problems profiles, suggesting that different pathways are involved for children in different profiles. On the one hand, the increased suicide attempt risk of children exposed to psychosocial adversities was largely explained by childhood emotional, behavioral, interpersonal problems and lower cognitive skills. Prevention of these problems across childhood may be helpful in order to reduce suicide attempt in youth. On the other hand, those symptoms explained a small proportion of the increased suicide attempt risk of children exposed to fetal growth adversities and parental mental health problems. This suggests that, to improve suicide prevention for those children, it is critical to identify other mechanisms implicated in the pathways to suicide attempt. Biological understanding of the consequences of fetal growth problems on the brain (Walhovd et al., 2012) and the role of pre-existing vulnerability to psychopathology (Nivard et al., 2017) is still poor, and research pointing in this direction may substantially contribute to better understand suicidal risk in those children.

\section{Strengths and limitations}

This study is based on large population-based cohorts with over 20 years of follow-up, allowing adequately powered analyses to study rare outcomes and exposures. Main findings have been replicated across the 2 independent samples, strengthening confidence in our conclusions. However, the following limitations should be noted. First, because of attrition, analyses were conducted on a subset of the initial representative samples. Although we used inverse probability weighting to account for the probability of missing at follow-up, caution should be used in generalizing our findings because unmeasured factors can still affect differential attrition. Second, both samples come from highincome western countries, therefore it is unknown if results will generalize to other populations. Third, despite the overall similarity in the measures of our perinatal factors across QLSCD and ALSPAC, important differences for some factors were present (e.g., maternal depression). Fourth, although we did not find any sex-interaction, our analyses might have not been powered enough to detect such differential associations for boys and girls. Fifth, although we investigated a wide range of perinatal factors, they are not an exhaustive list of all potential perinatal influences on suicide attempt. For example, inclusion of factors such as maternal nutrition, stressful life events, and exposure to specific drugs during pregnancy, exposure to traumatic events and violence (unmeasured in our study) 
may have helped us refining our latent classes. In the same way, it is important to acknowledge that other mediators that those investigated in this study may explain the observed associations, and future study should identify other potential pathways.

\section{Conclusions and implication of the findings}

Most research on the early risk factors for suicide focuses on the independent role of one (or few) factors. By using a comprehensive approach, this study showed that perinatal risk factors for suicide cluster in distinct profiles, which have specific associations with suicide attempt, as well as specific mediation pathways explaining these associations. This suggests that early-life suicide prevention requires health care professionals to adopt a multidisciplinary approach targeting a constellation of factors from different domains (psychological, obstetric, socioeconomic) to effectively reduce later vulnerability to suicide. Furthermore, the way these factors cluster together also determined the pathways leading to suicide attempt. Therefore, while potential interventions focusing on reducing the risk of childhood behavioral, emotional, interpersonal, and cognitive problems may substantially reduce suicide attempt risk for children exposed to socioeconomic adversity, targeting such factors may be less effective for children exposed to poor fetal growth and parental mental health problems. This information may help targeting suicide prevention interventions. 
Acknowledgements: This publication is the work of the authors and Drs Orri, Russell, Geoffroy, and Mars serve as guarantors for the contents of this paper. We are extremely grateful to all families who participated in the QLSCD, as well as all the professionals involved in the cohort project. We are extremely grateful to all the families who took part in this study, the midwives for their help in recruiting them, and the whole ALSPAC team, which includes interviewers, computer and laboratory technicians, clerical workers, research scientists, volunteers, managers, receptionists and nurses.

\section{Conflicts of Interest: None}

Financial support: This project is funded by a grant from the European Union's Horizon 2020 research and innovation program awarded to Dr Orri (\#793396), the Medical Research Foundation, and by the Medical Research Council (Grant ref: MR/R004889/1) Pathways to self-harm: Biological mechanisms and genetic contribution PI: Becky Mars. The UK Medical Research Council and Wellcome (Grant ref: 217065/Z/19/Z) and the University of Bristol provide core support for ALSPAC. A comprehensive list of grants funding is available on the ALSPAC website (http://www.bristol.ac.uk/alspac/external/documents/grant-acknowledgements.pdf); this research was specifically funded by the Wellcome Trust (Grant ref: GR067797MA and 217065/Z/19/Z). The Québec Longitudinal Study of Child Development was supported by funding from the ministère de la Santé et des Services sociaux, le ministère de la Famille, le ministère de l'Éducation et de l'Enseignement supérieur, the Lucie and André Chagnon Foundation, the Institut de recherche Robert-Sauvé en santé et en sécurité du travail, the Research Centre of the Sainte-Justine University Hospital, the ministère du Travail, de l'Emploi et de la Solidarité sociale and the Institut de la statistique du Québec. Additional funding was received by the Fonds de Recherche du Québec - Santé (FRQS), the Fonds de Recherche du Québec - Société et Culture (FRQSC), the Social Science and Humanities Research Council of Canada (SSHRC), the Canadian Institutes of Health Research (CIHR). Dr Geoffroy hold a Canada Research Chair (Tier 2) and a Young Investigator Award from the American Foundation for Suicide Prevention. Drs Turecki and Boivin hold a Canada Research Chair (Tier 1). Dr Turecki holds a NARSAD Distinguished Investigator Award and is supported by grants from the CIHR (FDN148374 and EGM141899). Drs Boivin, Geoffroy and Turecki are supported by the FRQS through the Quebec Network on Suicide, Mood Disorders and Related Disorders. Dr Tremblay is funded by the SSHRC. BM and DG were supported by the NIHR Biomedical Research Centre at University Hospitals Bristol NHS Foundation Trust and the University of Bristol.

Ethical standards: The authors assert that all procedures contributing to this work comply with the ethical standards of the relevant national and institutional committees on human experimentation and with the Helsinki Declaration of 1975 , as revised in 2008 . 


\section{References}

Aizer, A., \& Currie, J. (2014). The intergenerational transmission of inequality : Maternal disadvantage and health at birth. Science (New York, N.Y.), 344(6186), 856-861. https://doi.org/10.1126/science.1251872

Arsenault-Lapierre, G., Kim, C., \& Turecki, G. (2004). Psychiatric diagnoses in 3275 suicides : A meta-analysis. BMC Psychiatry, 4, 37. https://doi.org/10.1186/1471-244X-4-37

Bostwick, J. M., Pabbati, C., Geske, J. R., \& McKean, A. J. (2016). Suicide Attempt as a Risk Factor for Completed Suicide : Even More Lethal Than We Knew. American Journal of Psychiatry, 173(11), 1094-1100. https://doi.org/10.1176/appi.ajp.2016.15070854

Boyd, A., Golding, J., Macleod, J., Lawlor, D. A., Fraser, A., Henderson, J., ... Davey Smith, G. (2013). Cohort Profile: The 'children of the 90s'--the index offspring of the Avon Longitudinal Study of Parents and Children. International Journal of Epidemiology, 42(1), 111-127. https://doi.org/10.1093/ije/dys064

Cha, C. B., Franz, P. J., Guzmán, E., Glenn, C. R., Kleiman, E. M., \& Nock, M. K. (Ed). (2018). Annual Research Review : Suicide among youth - epidemiology, (potential) etiology, and treatment. Journal of Child Psychology and Psychiatry, 59(4), 460-482. https://doi.org/10.1111/jcpp.12831

Class, Q. A., Rickert, M. E., Larsson, H., Lichtenstein, P., \& D’Onofrio, B. M. (2014). Fetal growth and psychiatric and socioeconomic problems : Population-based sibling comparison. The British Journal of Psychiatry: The Journal of Mental Science, 205(5), 355-361. https://doi.org/10.1192/bjp.bp.113.143693

Cnattingius, S., Svensson, T., Granath, F., \& Iliadou, A. (2011). Maternal smoking during pregnancy and risks of suicidal acts in young offspring. European Journal of Epidemiology, 26(6), 485-492. https://doi.org/10.1007/s10654-011-9556-7

D’Onofrio, B. M., Class, Q. A., Rickert, M. E., Larsson, H., Långström, N., \& Lichtenstein, P. (2013). Preterm birth and mortality and morbidity : A population-based quasi-experimental study. JAMA Psychiatry, 70(11), 1231-1240. https://doi.org/10.1001/jamapsychiatry.2013.2107

D’Onofrio, B. M., Rickert, M. E., Frans, E., Kuja-Halkola, R., Almqvist, C., Sjölander, A., ... Lichtenstein, P. (2014). Paternal age at childbearing and offspring psychiatric and academic morbidity. JAMA Psychiatry, 71(4), 432-438. https://doi.org/10.1001/jamapsychiatry.2013.4525

Dunn, L., Thériault-Whalen, C., \& Dunn, L. (1993). EVIP: échelle de vocabulaire en images Peabody. Toronto, Canada: Psycan. 
Flensborg-Madsen, T., \& Mortensen, E. L. (2017). Birth Weight and Intelligence in Young Adulthood and Midlife. Pediatrics, 139(6), e20163161. https://doi.org/10.1542/peds.2016-3161

Fraser, A., Macdonald-Wallis, C., Tilling, K., Boyd, A., Golding, J., Davey Smith, G., ... Lawlor, D. A. (2013). Cohort Profile: The Avon Longitudinal Study of Parents and Children: ALSPAC mothers cohort. International Journal of Epidemiology, 42(1), 97-110. https://doi.org/10.1093/ije/dys066

Gale, C. R., \& Martyn, C. N. (2004). Birth weight and later risk of depression in a national birth cohort. The British Journal of Psychiatry: The Journal of Mental Science, 184, 28-33.

Geoffroy, M-C, Boivin, M., Arseneault, L., Renaud, J., Perret, L. C., Turecki, G., ... Côté, S. M. (2018). Childhood trajectories of peer victimization and prediction of mental health outcomes in midadolescence : A longitudinal population-based study. CMAJ, 190(2), E37-E43. https://doi.org/10.1503/cmaj.170219

Geoffroy, M-C, Boivin, M., Arseneault, L., Turecki, G., Vitaro, F., Brendgen, M., ... Côté, S. M. (2016). Associations Between Peer Victimization and Suicidal Ideation and Suicide Attempt During Adolescence : Results From a Prospective Population-Based Birth Cohort. Journal of the American Academy of Child \& Adolescent Psychiatry, 55(2), 99-105. https://doi.org/10.1016/j.jaac.2015.11.010

Geoffroy, M-C, Orri, M., Girard, A., Perret, L. C., \& Turecki, G. (2020). Trajectories of suicide attempts from early adolescence to emerging adulthood : Prospective 11-year follow-up of a Canadian cohort. Psychological Medicine, 1-11. https://doi.org/10.1017/S0033291720000732

Geoffroy, M.-C., Gunnell, D., \& Power, C. (2014). Prenatal and childhood antecedents of suicide : 50-year follow-up of the 1958 British Birth Cohort study. Psychological Medicine, 44(6), 1245-1256. https://doi.org/10.1017/S003329171300189X

Gobbi, G., Atkin, T., Zytynski, T., Wang, S., Askari, S., Boruff, J., ... Mayo, N. (2019). Association of Cannabis Use in Adolescence and Risk of Depression, Anxiety, and Suicidality in Young Adulthood: A Systematic Review and Meta-analysis. JAMA Psychiatry. https://doi.org/10.1001/jamapsychiatry.2018.4500

Goldman-Mellor, S. J., Caspi, A., Harrington, H., Hogan, S., Nada-Raja, S., Poulton, R., \& Moffitt, T. E. (2014). Suicide attempt in young people: A signal for long-term health care and social needs. JAMA Psychiatry, 71(2), 119-127. https://doi.org/10.1001/jamapsychiatry.2013.2803

Goodman, R. (1997). The Strengths and Difficulties Questionnaire : A Research Note. Journal of Child Psychology and Psychiatry, 38(5), 581-586. https://doi.org/10.1111/j.1469-7610.1997.tb01545.x 
Grote, N. K., Bridge, J. A., Gavin, A. R., Melville, J. L., Iyengar, S., \& Katon, W. J. (2010). A meta-analysis of depression during pregnancy and the risk of preterm birth, low birth weight, and intrauterine growth restriction. Archives of General Psychiatry, 67(10), 1012-1024.

https://doi.org/10.1001/archgenpsychiatry.2010.111

Gunnell, D. (2015). A Population Health Perspective on Suicide Research and Prevention. Crisis, 36(3), 155-160. https://doi.org/10.1027/0227-5910/a000317

Hawton, K., \& O’Connor, R. C. (2012). Self-harm in adolescence and future mental health. The Lancet, 379(9812), 198-199. https://doi.org/10.1016/S0140-6736(11)61260-9

Ladd, G. W., \& Kochenderfer-Ladd, B. (2002). Identifying victims of peer aggression from early to middle childhood : Analysis of cross-informant data for concordance, estimation of relational adjustment, prevalence of victimization, and characteristics of identified victims. Psychological Assessment, 14(1), 74-96. https://doi.org/10.1037/1040-3590.14.1.74

Lanza, S. T., \& Rhoades, B. L. (2013). Latent Class Analysis : An Alternative Perspective on Subgroup Analysis in Prevention and Treatment. Prevention Science, 14(2), 157-168. https://doi.org/10.1007/s11121-011-0201-1

Lim, K. X., Liu, C.-Y., Schoeler, T., Cecil, C. A. M., Barker, E. D., Viding, E., ... Pingault, J.-B. (2018). The role of birth weight on the causal pathway to child and adolescent ADHD symptomatology : A population-based twin differences longitudinal design. Journal of Child Psychology and Psychiatry, 59(10), 1036-1043. https://doi.org/10.1111/jcpp.12949

Mathewson, K. J., Chow, C. H. T., Dobson, K. G., Pope, E. I., Schmidt, L. A., \& Van Lieshout, R. J. (2017). Mental health of extremely low birth weight survivors : A systematic review and meta-analysis. Psychological Bulletin, 143(4), 347-383. https://doi.org/10.1037/bul0000091

Mittendorfer-Rutz, E., Rasmussen, F., \& Wasserman, D. (2004). Restricted fetal growth and adverse maternal psychosocial and socioeconomic conditions as risk factors for suicidal behaviour of offspring : A cohort study. The Lancet, 364(9440), 1135-1140. https://doi.org/10.1016/S0140-6736(04)17099-2

Murray, A. L., Eisner, M., \& Ribeaud, D. (2017). Can the Social Behavior Questionnaire Help Meet the Need for Dimensional, Transdiagnostic Measures of Childhood and Adolescent Psychopathology? European Journal of Psychological Assessment, 1-6. https://doi.org/10.1027/1015-5759/a000442

Muthén, L., \& Muthén, B. (1998-2017). Mplus User’s Guide. Seventh Edition. Los Angeles, CA: Muthén \& Muthén. 
Nivard, M. G., Gage, S. H., Hottenga, J. J., van Beijsterveldt, C. E. M., Abdellaoui, A., Bartels, M., ... Middeldorp, C. M. (2017). Genetic Overlap Between Schizophrenia and Developmental Psychopathology : Longitudinal and Multivariate Polygenic Risk Prediction of Common Psychiatric Traits During Development. Schizophrenia Bulletin, 43(6), 1197-1207. https://doi.org/10.1093/schbul/sbx031

Nock, M. K., Borges, G., Bromet, E. J., Cha, C. B., Kessler, R. C., \& Lee, S. (2008). Suicide and suicidal behavior. Epidemiologic Reviews, 30, 133-154. https://doi.org/10.1093/epirev/mxn002

Nock, M. K., Green, J. G., Hwang, I., McLaughlin, K. A., Sampson, N. A., Zaslavsky, A. M., \& Kessler, R. C. (2013). Prevalence, correlates, and treatment of lifetime suicidal behavior among adolescents : Results from the National Comorbidity Survey Replication Adolescent Supplement. JAMA Psychiatry, 70(3), 300-310. https://doi.org/10.1001/2013.jamapsychiatry.55

Nordsletten, A. E., Larsson, H., Crowley, J. J., Almqvist, C., Lichtenstein, P., \& Mataix-Cols, D. (2016). Patterns of Nonrandom Mating Within and Across 11 Major Psychiatric Disorders. JAMA Psychiatry, 73(4), $354-361$. https://doi.org/10.1001/jamapsychiatry.2015.3192

Northstone, K., Lewcock, M., Groom, A., Boyd, A., Macleod, J., Timpson, N., \& Wells, N. (2019). The Avon Longitudinal Study of Parents and Children (ALSPAC) : An update on the enrolled sample of index children in 2019. Wellcome Open Research, 4, 51. https://doi.org/10.12688/wellcomeopenres.15132.1

Nylund, K. L., Asparouhov, T., \& Muthén, B. O. (2007). Deciding on the Number of Classes in Latent Class Analysis and Growth Mixture Modeling : A Monte Carlo Simulation Study. Structural Equation Modeling: A Multidisciplinary Journal, 14(4), 535-569. https://doi.org/10.1080/10705510701575396

O’Donnell, K. J., \& Meaney, M. J. (2016). Fetal Origins of Mental Health : The Developmental Origins of Health and Disease Hypothesis. The American Journal of Psychiatry, appiajp201616020138. https://doi.org/10.1176/appi.ajp.2016.16020138

Orri, M., Scardena, S., Perret, L. C., Bolanis, D., Temcheff, C., Séguin, J. R., ... Geoffroy, M.-C. (2020). Mental Health Problems and Risk of Suicidal Ideation and Attempts in Adolescents. Pediatrics.

Orri, M., Galera, C., Turecki, G., Forte, A., Renaud, J., Boivin, M., ... Geoffroy, M.-C. (2018). Association of Childhood Irritability and Depressive/Anxious Mood Profiles With Adolescent Suicidal Ideation and Attempts. JAMA Psychiatry. https://doi.org/10.1001/jamapsychiatry.2018.0174 
Orri, M., Gunnell, D., Richard-Devantoy, S., Bolanis, D., Boruff, J., Turecki, G., \& Geoffroy, M.-C. (2019). In-utero and perinatal influences on suicide risk : A systematic review and meta-analysis. The Lancet Psychiatry, 6(6), 477-492. https://doi.org/10.1016/S2215-0366(19)30077-X

Orri, M., Perret, L. C., Turecki, G., \& Geoffroy, M.-C. (2018). Association between irritability and suicide-related outcomes across the life-course. Systematic review of both community and clinical studies. Journal of Affective Disorders. https://doi.org/10.1016/j.jad.2018.07.010

Orri, M., Pingault, J.-B., Rouquette, A., Lalanne, C., Falissard, B., Herba, C., ... Berthoz, S. (2017). Identifying affective personality profiles : A latent profile analysis of the Affective Neuroscience Personality Scales. Scientific Reports, 7(1), 4548. https://doi.org/10.1038/s41598-017-04738-x

Orri, M., Séguin, J. R., Castellanos-Ryan, N., Tremblay, R. E., Côté, S. M., Turecki, G., \& Geoffroy, M.-C. (2020). A genetically informed study on the association of cannabis, alcohol, and tobacco smoking with suicide attempt. Molecular Psychiatry, 1-10. https://doi.org/10.1038/s41380-020-0785-6

Parker, J. D., Schoendorf, K. C., \& Kiely, J. L. (1994). Associations between measures of socioeconomic status and low birth weight, small for gestational age, and premature delivery in the United States. Annals of Epidemiology, 4(4), 271-278. https://doi.org/10.1016/1047-2797(94)90082-5

Poulton, R., Caspi, A., Milne, B. J., Thomson, W. M., Taylor, A., Sears, M. R., \& Moffitt, T. E. (2002). Association between children's experience of socioeconomic disadvantage and adult health : A life-course study. Lancet (London, England), 360(9346), 1640-1645. https://doi.org/10.1016/S0140-6736(02)11602-3

Reinherz, H. Z., Tanner, J. L., Berger, S. R., Beardslee, W. R., \& Fitzmaurice, G. M. (2006). Adolescent suicidal ideation as predictive of psychopathology, suicidal behavior, and compromised functioning at age 30 . The American Journal of Psychiatry, 163(7), 1226-1232. https://doi.org/10.1176/appi.ajp.163.7.1226

Richard-Devantoy, S., Orri, M., Bertrand, J.-A., Greenway, K. T., Turecki, G., Gunnell, D., ... Geoffroy, M.-C. (2019). Childhood cognitive skill trajectories and suicide by mid-adulthood : An investigation of the 1958 British Birth Cohort. Psychological Medicine, 1-8. https://doi.org/10.1017/S0033291719003143

Turecki, G. (2005). Dissecting the suicide phenotype : The role of impulsive-aggressive behaviours. Journal of Psychiatry \& Neuroscience: JPN, 30(6), 398-408.

Turecki, G., \& Brent, D. A. (2016). Suicide and suicidal behaviour. Lancet (London, England), 387(10024), 1227-1239. https://doi.org/10.1016/S0140-6736(15)00234-2 
Vliegen, N., Casalin, S., \& Luyten, P. (2014). The course of postpartum depression : A review of longitudinal studies. Harvard Review of Psychiatry, 22(1), 1-22. https://doi.org/10.1097/HRP.0000000000000013

Walhovd, K. B., Fjell, A. M., Brown, T. T., Kuperman, J. M., Chung, Y., Hagler, D. J., .. for the Pediatric Imaging, N. (2012). Long-term influence of normal variation in neonatal characteristics on human brain development. Proceedings of the National Academy of Sciences, 201208180. https://doi.org/10.1073/pnas.1208180109

Wechsler, D. (1949). Wechsler Intelligence Scale for Children. San Antonio, TX, US: Psychological Corporation.

Wolke, D., Woods, S., Bloomfield, L., \& Karstadt, L. (2000). The association between direct and relational bullying and behaviour problems among primary school children. Journal of Child Psychology and Psychiatry, and Allied Disciplines, 41(8), 989-1002. 
Table 1. Description of the perinatal adversity measures in QLSCD and ALSPAC

\begin{tabular}{|c|c|c|}
\hline & QLSCD & ALSPAC \\
\hline \multicolumn{3}{|l|}{ Fetal growth adversities } \\
\hline Short birth length & $<47 \mathrm{vs} \geq 47 \mathrm{~cm}^{\mathrm{a}}$ & $<47 \mathrm{vs} \geq 47 \mathrm{~cm}$ \\
\hline Low birth weight & $<2500 \mathrm{vs} \geq 2500$ grams $^{\mathrm{a}}$ & $<2500$ vs $\geq 2500$ grams \\
\hline Short head circumference & $<10$ th percentile $(32 \mathrm{~cm})$ vs $\geq 10$ th percentile ${ }^{a}$ & $<10$ th percentile $(33 \mathrm{~cm})$ vs $\geq 10$ th percentile \\
\hline Growth restriction & $\begin{array}{l}\text { Intrauterine growth retardation suspected during } \\
\text { pregnancy before onset of labor }{ }^{\text {a }}\end{array}$ & $\begin{array}{l}\text { Intrauterine growth retardation suspected during } \\
\text { pregnancy before onset of labor }{ }^{\mathrm{a}}\end{array}$ \\
\hline Prematurity & $<37$ vs $\geq 37$ weeks of gestational age $\mathrm{a}^{\mathrm{a}}$ & $<37$ vs $\geq 37$ weeks of gestational age \\
\hline \multicolumn{3}{|l|}{ Pregnancy complications } \\
\hline Mother hemorrhage & Hemorrhage during childbirth (ICD-9 code 641) ${ }^{\mathrm{a}}$ & Hemorrhage prior to delivery ${ }^{\mathrm{b}}$ \\
\hline Mother hypertension & $\begin{array}{l}\text { Hypertension complicating pregnancy (ICD-9 code } \\
642)^{\mathrm{b}}\end{array}$ & $\begin{array}{l}\text { Gestational hypertension without pre-existing } \\
\text { hypertension }{ }^{\mathrm{b}}\end{array}$ \\
\hline Mother diabetes & $\begin{array}{l}\text { Diabetes mellitus complicating pregnancy childbirth } \\
\text { (ICD-9 code } 648.0)^{\mathrm{b}}\end{array}$ & Diabetes noted during pregnancy before onset of labor ${ }^{b}$ \\
\hline \multicolumn{3}{|l|}{ Birth/delivery adversities } \\
\hline Long hospitalization & Baby discharged from hospital $>3$ days after birth ${ }^{a}$ & Baby discharged from hospital $>3$ days after birth ${ }^{a}$ \\
\hline Transfer hospital & Transfer to a specialized hospital ${ }^{\text {a }}$ & $\begin{array}{l}\text { Yes to the question: "Was your baby admitted to a } \\
\text { special care baby unit or neonatal intensive care unit or } \\
\text { other hospital ward?" b }\end{array}$ \\
\hline Low APGAR & APGAR score 5 minutes $<7^{\text {a }}$ & APGAR score 5 minutes $<7^{\text {a }}$ \\
\hline Birth induction & Induced delivery ${ }^{a}$ & Induced delivery ${ }^{a}$ \\
\hline Delivery acceleration & Labor augmented ${ }^{\mathrm{a}}$ & Labor augmented $^{\mathrm{a}}$ \\
\hline Caesarean section & Method of delivery as Caesarean a & Method of delivery as Caesarean ${ }^{a}$ \\
\hline Child hypoxia/asphyxia & ICD-9 code $766^{\text {a }}$ & Not available \\
\hline \multicolumn{3}{|l|}{ Socioeconomic adversities } \\
\hline Low maternal education & $\begin{array}{l}\text { Did not obtain high school diploma at child age } 5 \\
\text { months }{ }^{\text {b }}\end{array}$ & Did not obtain GCSE at 32 w. gestation ${ }^{\text {b,d }}$ \\
\hline Low paternal education & $\begin{array}{l}\text { Did not obtain high school diploma at child age } 5 \\
\text { months }{ }^{c}\end{array}$ & Did not obtain GCSE at 32 w. gestation ${ }^{\text {b,d }}$ \\
\hline Low socioeconomic status & $\begin{array}{l}<25 \text { th percentile - measured using a standardized } \\
\text { aggregate index of five items relating to parental } \\
\text { education, parental occupation, and annual gross } \\
\text { income (Willms \& Shields, 1996) }\end{array}$ & $\begin{array}{l}<25 \text { th percentile- derived from housing tenure, } \\
\text { employment, education and social class (maternal and } \\
\text { paternal) during pregnancy }\end{array}$ \\
\hline Nonintact family & $\begin{array}{l}\text { Biological father not living with study child and } \\
\text { mother at child age } 5 \text { months }\end{array}$ & $\begin{array}{l}\text { Father or partner not living with study child and } \\
\text { mother within one year of birth }{ }^{\mathrm{b}}\end{array}$ \\
\hline Low maternal age & $<20$ years old at childbirth ${ }^{\text {b }}$ & $<20$ years old at childbirth ${ }^{\text {b }}$ \\
\hline Advanced paternal age & $>35$ years old at childbirth ${ }^{c}$ & $>35$ years old at childbirth ${ }^{c}$ \\
\hline High birth order & 4th or later born reported at child age 5 months ${ }^{\text {b }}$ & 4th or later born reported at 32 weeks of gestation ${ }^{\text {b }}$ \\
\hline \multicolumn{3}{|l|}{ Exposures during pregnancy } \\
\hline Maternal smoking & Smoked tobacco during any trimester of pregnancy ${ }^{\mathrm{b}}$ & Smoked tobacco during any trimester of pregnancy ${ }^{\mathrm{b}}$ \\
\hline Maternal alcohol use & $\begin{array}{l}>1 \text { glass per week alcohol during any trimester of } \\
\text { pregnancy at child age } 5 \text { months }\end{array}$ & $\begin{array}{l}>1 \text { glass per week alcohol use in 1st trimester and/or } \\
\text { last } 2 \text { months of pregnancy }{ }^{b}\end{array}$ \\
\hline Maternal drug use & $\begin{array}{l}\text { Use of any illicit drug during pregnancy at child age } 5 \\
\text { months }{ }^{b}\end{array}$ & $\begin{array}{l}\text { Use of any of amphetamines, barbiturates, crack, } \\
\text { cocaine, heroin, methadone, ecstasy, or other drug } \\
\text { during pregnancy }\end{array}$ \\
\hline Maternal medication use & $\begin{array}{l}\text { Use of any medication (prescribed and over-the- } \\
\text { counter) during any trimester of pregnancy }{ }^{b}\end{array}$ & $\begin{array}{l}\text { Use of any medication for any of nausea, heartburn, } \\
\text { vomiting, anxiety, infection, migraine, difficulty with } \\
\text { sleep, pain, allergies, skin conditions, bleeding, } \\
\text { depression, piles, constipation, cough or other reason } \\
\text { during pregnancy }\end{array}$ \\
\hline \multicolumn{2}{|l|}{ Parental mental health problems } & $\mathrm{EPDS} \geq 13^{\mathrm{b}}$ \\
\hline Paternal depression & CESD short version $>2.67^{\circ}$ & EPDS $\geq 13$ at child age 8 months (partner-reported) \\
\hline Maternal anxiety & Not available & $\mathrm{CCEI} \geq 8^{\mathrm{b}}$ \\
\hline Paternal anxiety & Not available & $\mathrm{CCEI} \geq 8^{\mathrm{c}}$ \\
\hline Maternal antisocial behavior & $\begin{array}{l}\geq 2 \text { out of } 5 \text { conduct problems based on the DSM-IV } \\
\text { criteria for conduct and antisocial personality } \\
\text { disorders }{ }^{b}\end{array}$ & Not available \\
\hline Paternal antisocial behavior & $\begin{array}{l}\geq 2 \text { out of } 5 \text { conduct problems based on the DSM-IV } \\
\text { criteria for conduct and antisocial personality } \\
\text { disorders }\end{array}$ & Not available \\
\hline
\end{tabular}

${ }^{a}$ From medical records; ${ }^{b}$ Mother-reported; ${ }^{\mathrm{c}}$ Father/partner-reported; ${ }^{\mathrm{d}}$ collected at 32 weeks of gestation

Mother and father reports have been collected when the children were 5 months of age in QLSCD and 8 months of age in

ALSPAC (where not otherwise specified).

APGAR: Appearance, Pulse, Grimace, Activity, and Respiration; CCEI: Crown Crisp Experiential Index; CESD: Centre for Epidemiological Study Depression Scale; DSM: Diagnostic and Statistical Manual of Mental Disorders; EPDS: Edinburgh Postnatal Depression Scale; GCSE: General Certificate of Secondary Education - age 16; ICD: International Classification of Diseases. 
Table 2. Distribution of perinatal adversities in QLSCD and ALSPAC, and association with suicide attempt

\begin{tabular}{|c|c|c|c|c|c|c|c|c|c|}
\hline \multirow[b]{3}{*}{ Early-life adversity } & \multicolumn{4}{|c|}{ QLSCD $^{\mathrm{a}}, \mathrm{N}=1623$} & \multicolumn{4}{|c|}{ ALSPAC, $N=5734$} & \multirow{3}{*}{$\begin{array}{c}\text { Combined }^{\mathrm{b}}, \mathrm{N}=7357 \\
\text { OR }(95 \% \mathrm{CI})\end{array}$} \\
\hline & \multirow{2}{*}{$\begin{array}{l}\text { n (\%) in the } \\
\text { sample }\end{array}$} & \multicolumn{2}{|c|}{$\mathrm{n}(\%)$ by suicide attempt } & \multirow[b]{2}{*}{ OR $(95 \% \mathrm{CI})$} & \multirow[b]{2}{*}{$\begin{array}{l}\mathrm{n}(\%) \text { in the } \\
\text { sample }\end{array}$} & \multicolumn{2}{|c|}{$\mathrm{n}(\%)$ by suicide attempt } & \multirow[b]{2}{*}{ OR $(95 \% \mathrm{CI})$} & \\
\hline & & $\begin{array}{c}\text { Yes } \\
134 \\
(8.3 \%)\end{array}$ & $\begin{array}{c}\text { No } \\
1489(91.7 \%)\end{array}$ & & & $\begin{array}{c}\text { Yes } \\
484(8.4 \%)\end{array}$ & $\begin{array}{c}\text { No } \\
5250(91.6 \%)\end{array}$ & & \\
\hline \multicolumn{10}{|l|}{ Fetal growth adversities } \\
\hline Short birth length & $130(8.7)$ & $13(10.4)$ & $117(8.5)$ & $1.28(0.72-2.13)$ & $158(4.3)$ & $12(4.1)$ & $146(4.3)$ & $0.84(0.45-1.56)$ & $1.06(0.71-1.59)$ \\
\hline Low birth weight & $51(3.1)$ & $<5(3.7)$ & $\geq 46(\geq 3.0)$ & $1.31(0.50-2.87)$ & $227(4.0)$ & $28(5.9)$ & $199(3.8)$ & $1.57(1.04-2.37)$ & $1.52(1.05-2.20)$ \\
\hline Short head circumference & $133(8.2)$ & $17(12.7)$ & $116(7.8)$ & $1.87(1.10-3.04)$ & $349(7.7)$ & $37(9.9)$ & $312(7.5)$ & $1.17(0.81-1.69)$ & $1.43(0.91-2.26)$ \\
\hline Growth restriction & $129(8)$ & $13(9.7)$ & $116(7.8)$ & $1.44(0.79-2.45)$ & $98(2.8)$ & $9(2.8)$ & $89(2.8)$ & $1.02(0.51-2.04)$ & $1.26(0.81-1.95)$ \\
\hline Prematurity & $78(4.8)$ & $9(6.7)$ & $69(4.6)$ & $1.30(0.59-2.51)$ & $261(4.6)$ & $21(4.3)$ & $240(4.6)$ & $0.97(0.61-1.53)$ & $1.05(0.72-1.55)$ \\
\hline \multicolumn{10}{|l|}{ Pregnancy complications } \\
\hline Mother hemorrhage & $47(2.9)$ & $<5(<3.7)$ & $\geq 42(\geq 2.8)$ & $0.29(0.04-1.06)$ & $25(0.8)$ & $<5(<1.6)$ & $\geq 24(\geq 0.8)$ & $0.37(0.05-2.77)$ & $0.32(0.09-1.11)$ \\
\hline Mother hypertension & $62(3.8)$ & $5(3.7)$ & $57(3.8)$ & $1.15(0.46-2.44)$ & $806(14.4)$ & $54(11.5)$ & $752(14.7)$ & $0.78(0.58-1.05)$ & $0.82(0.62-1.08)$ \\
\hline Mother diabetes & $5(0.3)$ & $<5(<3.7)$ & $\leq 5(\leq 0.3)$ & NA & $32(0.9)$ & $5(1.6)$ & $27(0.8)$ & $1.93(0.73-5.09)$ & $1.93(0.73-5.09)$ \\
\hline \multicolumn{10}{|l|}{ Birth/delivery adversities } \\
\hline Long hospitalization & $130(8.2)$ & $9(6.9)$ & $121(8.3)$ & $0.93(0.44-1.76)$ & $1477(44.3)$ & $122(40.7)$ & $1355(44.7)$ & $0.88(0.69-1.12)$ & $0.89(0.71-1.12)$ \\
\hline Transfer hospital & $24(1.9)$ & $<5(<3.7)$ & $\geq 19(\geq 1.3)$ & $0.36(0.01-2.02)$ & $319(5.8)$ & $30(6.5)$ & $289(5.7)$ & $1.24(0.84-1.84)$ & $1.15(0.63-2.09)$ \\
\hline low APGAR & $25(1.6)$ & $<5(<3.7)$ & $\geq 19(\geq 1.3)$ & $1.65(0.38-4.88)$ & $28(0.8)$ & $<5(<1.6)$ & $\geq 24(\geq 0.8)$ & $1.91(0.68-5.37)$ & $1.80(0.81-3.96)$ \\
\hline Birth induction & $495(31.3)$ & $43(32.6)$ & $452(31.2)$ & $1.04(0.73-1.48)$ & $656(19.1)$ & $56(18.1)$ & $600(19.2)$ & $0.99(0.73-1.34)$ & $1.01(0.80-1.27)$ \\
\hline Delivery acceleration & $756(51.9)$ & $60(52.2)$ & $696(51.9)$ & $0.94(0.66-1.34)$ & $1982(63.9)$ & $177(62.3)$ & $1805(64.0)$ & $0.94(0.73-1.22)$ & $0.94(0.77-1.16)$ \\
\hline Caesarean section & $242(15)$ & $17(12.8)$ & $225(15.2)$ & $0.82(0.49-1.31)$ & $581(10.4)$ & $51(10.9)$ & $530(10.3)$ & $1.07(0.79-1.46)$ & $0.99(0.76-1.29)$ \\
\hline Child hypoxia/asphyxia & $154(9.5)$ & $13(9.7)$ & $141(9.5)$ & $1.13(0.62-1.91)$ & & & & & \\
\hline \multicolumn{10}{|l|}{ Socioeconomic adversities } \\
\hline Low maternal education & $273(16.8)$ & $26(19.5)$ & $247(16.6)$ & $1.42(0.89-2.19)$ & $1129(20.3)$ & $101(21.6)$ & $1028(20.2)$ & $1.04(0.83-1.31)$ & $1.14(0.86-1.51)$ \\
\hline Low paternal education & $251(16.8)$ & $28(23.9)$ & $223(16.2)$ & $1.81(1.15-2.76)$ & $1341(24.7)$ & $128(28.4)$ & $1213(24.4)$ & $1.17(0.94-1.45)$ & $1.39(0.91-2.11)$ \\
\hline Low socioeconomic status & $370(23)$ & $41(31.1)$ & $329(22.3)$ & $1.76(1.18-2.57)$ & $513(14.1)$ & $59(20.2)$ & $454(13.6)$ & $1.56(1.16-2.11)$ & $1.64(1.29-2.08)$ \\
\hline Nonintact family & $300(18.6)$ & $34(25.4)$ & $266(17.9)$ & $1.69(1.13-2.48)$ & $343(6.2)$ & $53(11.4)$ & $290(5.7)$ & $2.10(1.54-2.87)$ & $1.93(1.51-2.47)$ \\
\hline Low maternal age & $39(2.4)$ & $5(3.7)$ & $34(2.3)$ & $1.96(0.59-5.01)$ & $105(1.8)$ & $16(3.3)$ & $89(1.7)$ & $1.85(1.08-3.18)$ & $1.87(1.16-3.02)$ \\
\hline Advanced paternal age & $444(29.5)$ & $23(19.7)$ & $421(30.3)$ & $0.57(0.37-0.86)$ & $804(20.1)$ & $84(24.6)$ & $720(19.7)$ & $1.39(1.07-1.81)$ & $0.91(0.38-2.15)$ \\
\hline High birth order & $71(4.4)$ & $8(6.0)$ & $63(4.2)$ & $1.33(0.59-2.65)$ & $513(9.2)$ & $39(8.3)$ & $474(9.3)$ & $0.86(0.61-1.21)$ & $0.94(0.66-1.34)$ \\
\hline \multicolumn{10}{|l|}{ Exposures during pregnancy } \\
\hline Maternal smoking & $393(24.3)$ & $44(33.8)$ & $349(23.5)$ & $1.86(1.29-2.64)$ & $1050(18.4)$ & $143(29.7)$ & $907(17.4)$ & $1.97(1.60-2.43)$ & $1.94(1.62-2.32)$ \\
\hline Maternal alcohol use & $622(38.5)$ & $46(35.4)$ & $576(38.8)$ & $0.85(0.61-1.19)$ & $1677(29.6)$ & $141(29.6)$ & $1536(29.6)$ & $1.04(0.84-1.27)$ & $0.98(0.82-1.17)$ \\
\hline Maternal drug use & $22(1.4)$ & $<5(<3.7)$ & $\geq 19(\geq 1.3)$ & $2.59(0.74-7.01)$ & $284(5.0)$ & $28(5.8)$ & $256(4.9)$ & $1.19(0.79-1.79)$ & $1.48(0.75-2.91)$ \\
\hline Maternal medication use & $1026(63.6)$ & $79(60.8)$ & $947(63.9)$ & $0.88(0.63-1.24)$ & $3711(66.1)$ & $328(69.6)$ & $3383(65.8)$ & $1.22(0.99-1.49)$ & $1.07(0.79-1.45)$ \\
\hline \multicolumn{10}{|l|}{ Parental mental health problems } \\
\hline Maternal depression & $222(13.7)$ & $24(18.2)$ & $198(13.3)$ & $1.47(0.94-2.25)$ & $403(7.6)$ & $52(11.7)$ & $351(7.2)$ & $1.74(1.27-2.37)$ & $1.64(1.27-2.12)$ \\
\hline Paternal depression & $80(5.7)$ & $7(6.4)$ & $73(5.7)$ & $1.02(0.44-2.04)$ & $99(2.6)$ & $11(3.4)$ & $88(2.5)$ & $1.23(0.65-2.33)$ & $1.14(0.70-1.85)$ \\
\hline Maternal anxiety & NÁ & NA & NA & NA & $1346(25.2)$ & $139(31.2)$ & $1207(24.7)$ & $1.39(1.12-1.72)$ & $1.39(1.12-1.72)$ \\
\hline Paternal anxiety & NA & NA & NA & NA & $166(4.3)$ & $16(4.9)$ & $150(4.2)$ & $1.10(0.64-1.89)$ & $1.10(0.64-1.89)$ \\
\hline Maternal antisocial behavior & $315(20.2)$ & $27(21.3)$ & $288(20.1)$ & $1.27(0.83-1.88)$ & NA & NÁ & NA & NA & $1.27(0.85-1.91)$ \\
\hline Paternal antisocial behavior & $326(23.4)$ & $35(32.1)$ & $291(22.7)$ & $1.94(1.31-2.84)$ & NA & NA & NA & NA & $1.93(1.32-2.84)$ \\
\hline
\end{tabular}

Odds Ratios (OR) are adjusted for sex and estimated using inverse probability weighing to account for attrition 
aData were compiled from the final master file of the Québec Longitudinal Study of Child Development (1998-2018), CGouvernement du Québec, Institut de la statistique du Québec. ${ }^{b} \mathrm{OR}$ were pooled using fixed-effect meta-analysis

Number below 5 and associated proportion have been rounded at $<5$ (data reporting rule to ensure confidentiality). This may contain zero.

NA, Not Available 
Table 3. Direct and indirect effect of perinatal adversity profiles on suicide attempt in QLSCD, ALSPAC, and pooled estimates

\begin{tabular}{|c|c|c|c|c|c|c|c|c|c|}
\hline \multirow[b]{2}{*}{$\begin{array}{l}\text { Early-life adversity } \\
\text { profile and mediator }\end{array}$} & \multicolumn{3}{|l|}{ QLSCD $^{\mathrm{a}}$} & \multicolumn{3}{|l|}{ ALSPAC } & \multicolumn{3}{|l|}{ Combined $^{\mathrm{b}}$} \\
\hline & $\begin{array}{l}\text { Direct effect } \\
\text { OR }(95 \% \mathrm{CI})\end{array}$ & $\begin{array}{l}\text { Indirect effect } \\
\text { OR }(95 \% \mathrm{CI})\end{array}$ & $\begin{array}{l}\text { \% } \\
\text { mediated }\end{array}$ & $\begin{array}{l}\text { Direct effect } \\
\text { OR }(95 \% \mathrm{CI})\end{array}$ & $\begin{array}{l}\text { Indirect effect } \\
\text { OR }(95 \% \mathrm{CI})\end{array}$ & $\begin{array}{l}\text { \% } \\
\text { mediated }\end{array}$ & $\begin{array}{l}\text { Direct effect } \\
\text { OR }(95 \% \mathrm{CI})\end{array}$ & $\begin{array}{l}\text { Indirect effect } \\
\text { OR }(95 \% \mathrm{CI})\end{array}$ & $\begin{array}{l}\% \\
\text { mediated }\end{array}$ \\
\hline \multicolumn{10}{|l|}{ Poor fetal growth } \\
\hline Emotional problems & $2.64(1.26-5.53)$ & $1.08(0.99-1.17)$ & 7.1 & $1.45(0.98-2.14)$ & $1.04(1.00-1.07)$ & 9.1 & $1.79(1.03-3.14)$ & $1.04(1.01-1.08)$ & 6.5 \\
\hline Behavioral problems & $2.65(1.24-5.67)$ & $1.07(0.99-1.15)$ & 6.0 & $1.46(0.99-2.15)$ & $1.03(1.00-1.06)$ & 3.0 & $1.79(1.03-3.12)$ & $1.03(1.01-1.06)$ & 5.3 \\
\hline Hyperactivity-impulsivity & $2.55(1.19-5.47)$ & $1.11(1.01-1.22)$ & 10.0 & $1.43(0.97-2.12)$ & $1.05(1.01-1.09)$ & 12.0 & $1.74(1.02-2.96)$ & $1.06(1.02-1.11)$ & 9.2 \\
\hline Peer victimization & $2.76(1.29-5.88)$ & $1.03(0.98-1.10)$ & 3.2 & $1.46(0.99-2.15)$ & $1.03(0.99-1.06)$ & 6.6 & $1.84(1.01-3.36)$ & $1.03(1.00-1.06)$ & 4.5 \\
\hline Cognitive skills & $2.70(1.28-5.67)$ & $1.04(0.97-1.12)$ & 4.1 & $1.47(1.00-2.17)$ & $1.02(0.98-1.06)$ & 4.8 & $1.83(1.04-3.23)$ & $1.02(0.99-1.06)$ & 3.9 \\
\hline All mediators & $2.46(1.17-5.18)$ & $1.15(1.02-1.31)$ & 13.7 & $1.39(0.9-2.06)$ & $1.08(1.02-1.15)$ & 19.6 & 1.69 (0.99 2.88) & $1.10(1.04-1.16)$ & 15.0 \\
\hline \multicolumn{10}{|l|}{ Socioeconomic adversity } \\
\hline Emotional problems & $1.58(0.98-2.54)$ & $1.13(1.04-1.22)$ & 20.5 & $1.27(0.99-1.64)$ & $1.03(1.01-1.05)$ & 10.2 & $1.33(1.07-1.67)$ & $1.07(0.98-1.16)$ & 17.9 \\
\hline Behavioral problems & $1.58(0.98-2.54)$ & $1.13(1.03-1.23)$ & 20.7 & $1.26(0.98-1.63)$ & $1.04(1.01-1.07)$ & 4.0 & $1.33(1.06-1.66)$ & $1.07(0.99-1.16)$ & 19.5 \\
\hline Hyperactivity-impulsivity & $1.57(0.99-2.50)$ & $1.13(1.04-1.22)$ & 20.8 & $1.23(0.96-1.59)$ & $1.07(1.03-1.11)$ & 23.4 & $1.30(1.04-1.63)$ & $1.08(1.03-1.14)$ & 22.3 \\
\hline Peer victimization & $1.62(1.01-2.58)$ & $1.10(1.03-1.18)$ & 16.6 & $1.24(0.97-1.60)$ & $1.05(1.02-1.08)$ & 18.0 & $1.32(1.06-1.65)$ & $1.06(1.02-1.11)$ & 17.4 \\
\hline Cognitive skills & $1.67(1.03-2.68)$ & $1.08(0.97-1.20)$ & 13.0 & $1.26(0.97-1.64)$ & $1.04(0.97-1.12)$ & 15.4 & $1.34(1.07-1.69)$ & $1.05(0.99-1.12)$ & 14.7 \\
\hline All mediators & $1.43(0.87-2.34$ & $1.23(1.07-1.43)$ & 37.1 & $1.18(0.91-1.53)$ & $1.10(1.02-1.19)$ & 37.1 & $1.23(0.97-1.55)$ & $1.15(1.03-1.28)$ & 39.9 \\
\hline \multicolumn{10}{|l|}{$\begin{array}{l}\text { Parental mental health } \\
\text { problems }\end{array}$} \\
\hline Emotional problems & & & & $1.67(1.21-2.31)$ & $1.03(1.01-1.06)$ & 6.1 & & & \\
\hline Behavioral problems & & & & $1.70(1.24-2.33)$ & $1.03(1.00-1.05)$ & 4.9 & & & \\
\hline Hyperactivity-impulsivity & & & & $1.67(1.22-2.28)$ & $1.05(1.01-1.08)$ & 8.3 & & & \\
\hline Peer victimization & & & & $1.70(1.24-2.33)$ & $1.03(1.00-1.06)$ & 4.7 & & & \\
\hline Cognitive skills & & & & $1.71(1.25-2.35)$ & $1.02(0.99-1.04)$ & 2.7 & & & \\
\hline All mediators & & & & $1.62(1.18-2.23)$ & $1.08(1.03-1.13)$ & 13.6 & & & \\
\hline
\end{tabular}

aData were compiled from the final master file of the Québec Longitudinal Study of Child Development (1998-2018), CGouvernement du Québec, Institut de la statistique du Québec

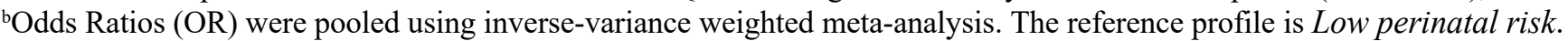

The indirect is the association between perinatal adversity profiles and suicide attempt through mediators, while the direct effects is the association between perinatal adversity profiles and suicide attempt independently from (i.e., not explained by) the mediators. 
Figure 1. Perinatal profiles identified using latent class analysis in $\mathrm{QLSCD}^{\mathrm{a}}$ and ALSPAC
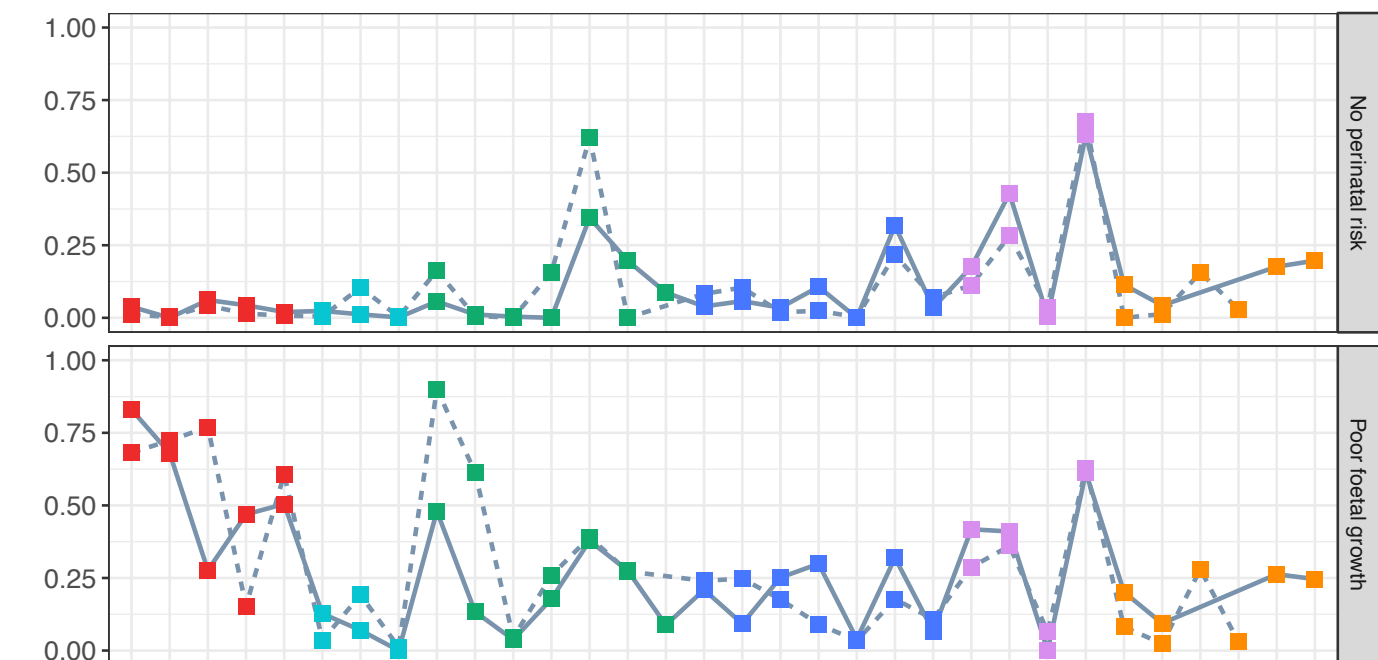

Cohort

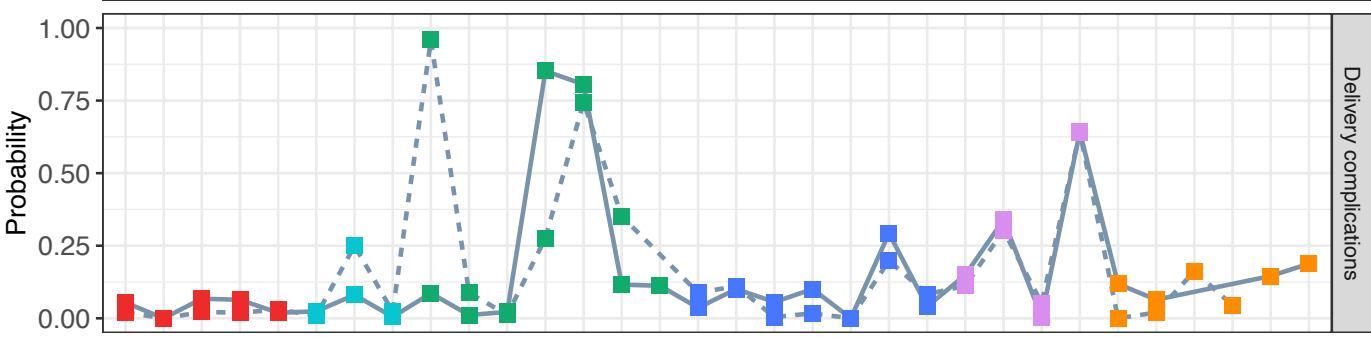

- QLSCD

- - ALSPAC

Perinatal adversity group

- Fetal growth

- Pregnancy complications

- Perinatal complications

- Socioeconomic

- Substance exposure

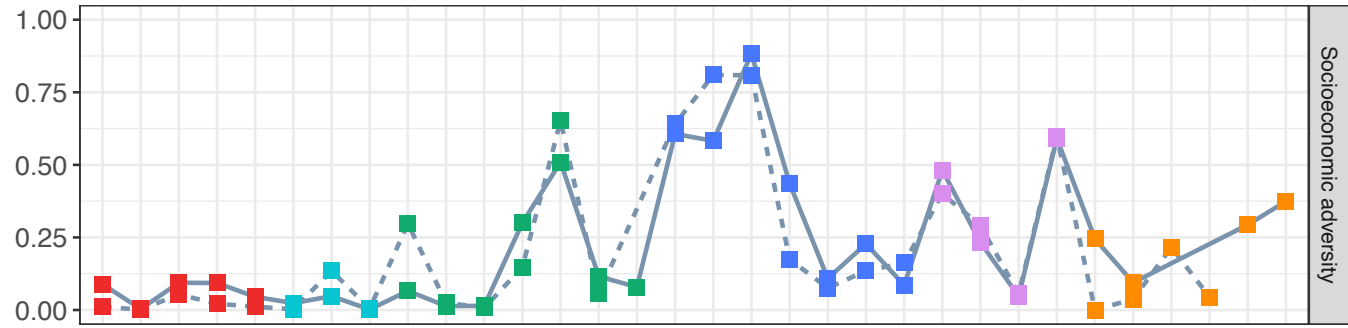

- Parental mental health problems

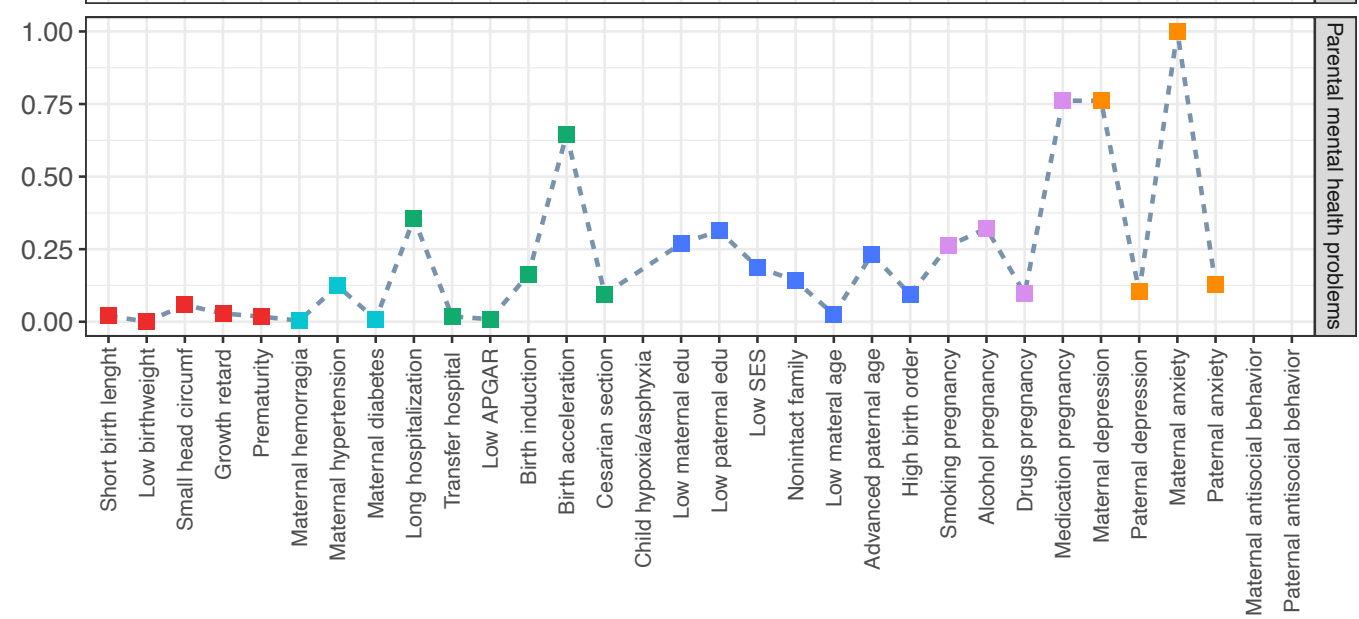

Perinatal adversities

a Data were compiled from the final master file of the Québec Longitudinal Study of Child Development (1998-2018),

CGouvernement du Québec, Institut de la statistique du Québec

Perinatal adversity profiles estimated using Latent Class Analysis in the Québec Longitudinal Study of Child Development (QLSCD, N=1623; solid lines) and in the Avon Longitudinal Study of Parents and Children (ALSPAC, N=5735; dotted lines). For each profile (indicated in the right-end panel label). The y-axis represents the estimated probability for each perinatal adversity (reported in the x-axis), that we color coded according to the groups of perinatal adversities.

Entropy was 0.813 in QLSCD and 0.732 in ALSPAC.

SES, Socioeconomic status 
Figure 2. Comparison between the prevalence of perinatal adversities in each adversity profile compared to the reference profile in QLSCD and ALSPAC
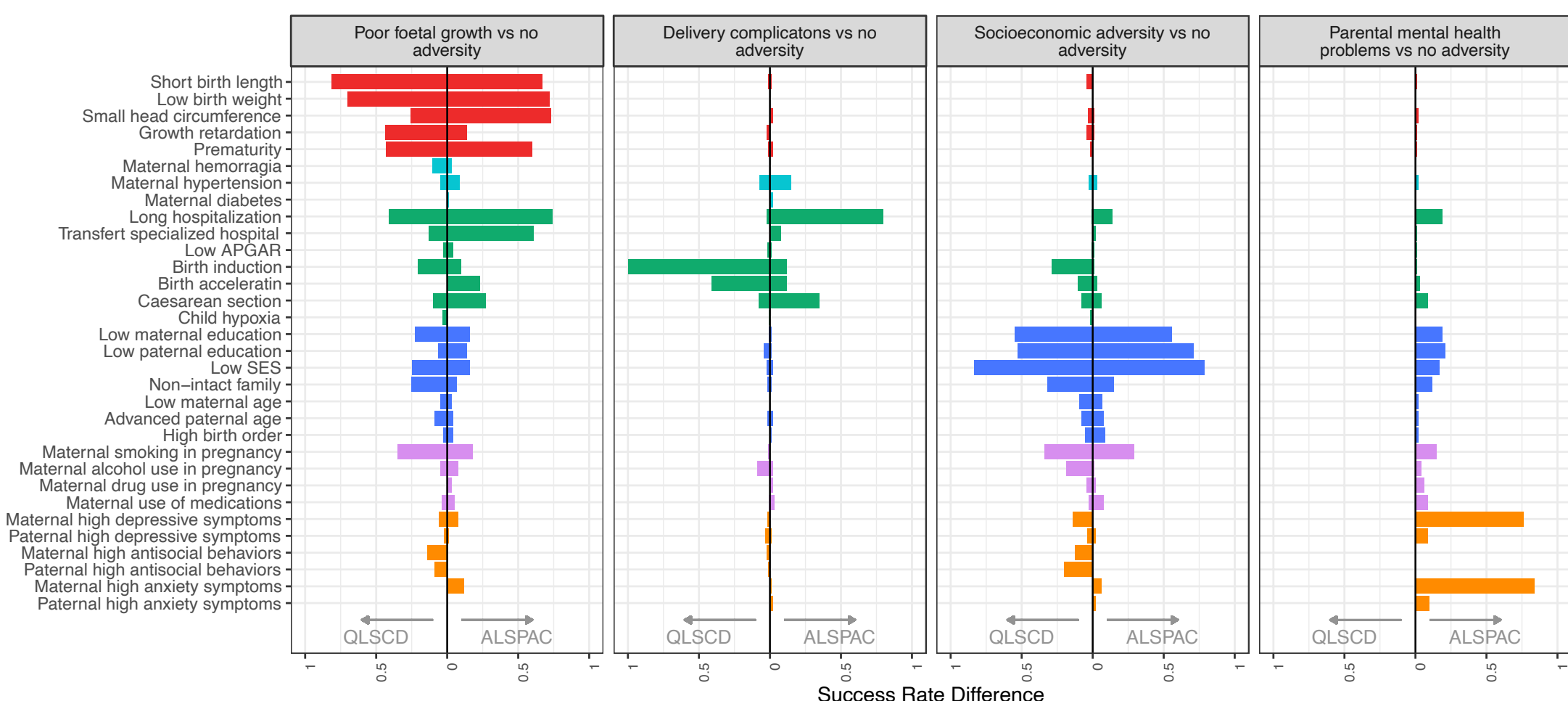

Perinatal adversity groups

Foetal growth adversity

Pregnancy complications

Birth/delivery adversity

Socioeconomic adversity

Exposures during pregnancy

Parental mental health problems

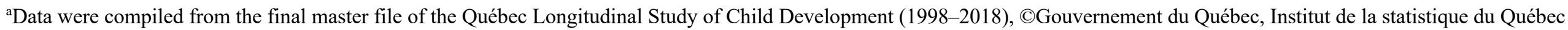

For each perinatal adversity profile (panel), the figure shows the difference between the prevalence of each perinatal factor (y-axis) in each perinatal adversity profile vs. the reference profile (Low perinatal risk profile) in the Québec Longitudinal Study of Child Development (QLSCD, N=1623; left side of each panel) and in the Avon Longitudinal Study of Parents and Children (ALSPAC, N=5735; right side). Comparison of the prevalence was done using the Success Rate Difference (SRD), a measure of effect size computed as follows: SRD= (rate group 1 - rate reference group). For example, in QLSCD, the difference in short birth length rate between children in the Poor fetal growth profiles vs No perinatal risk profile was $81 \%$ (see first panel, left side), while for children in the Socioeconomic adversity profile, this difference was $4 \%$ (see third panel, left side). SES, Socioeconomic status 
Online only supplement

Perinatal adversity profiles and suicide attempt in adolescence and young adulthood: Longitudinal analyses from two 20-year birth cohort studies

Massimiliano Orri, Abigail E. Russell, Becky Mars, Gustavo Turecki, David Gunnell, Jon Heron, Richard E. Tremblay, Michel Boivin, Anne-Monique Nuyt, Sylvana M. Côté, Marie-Claude Geoffroy 
Table S1. Rate of each perinatal factor and sex in the analysis sample and in the nonincluded sample, for QLSCD ${ }^{\mathrm{a}}$ and ALSPAC

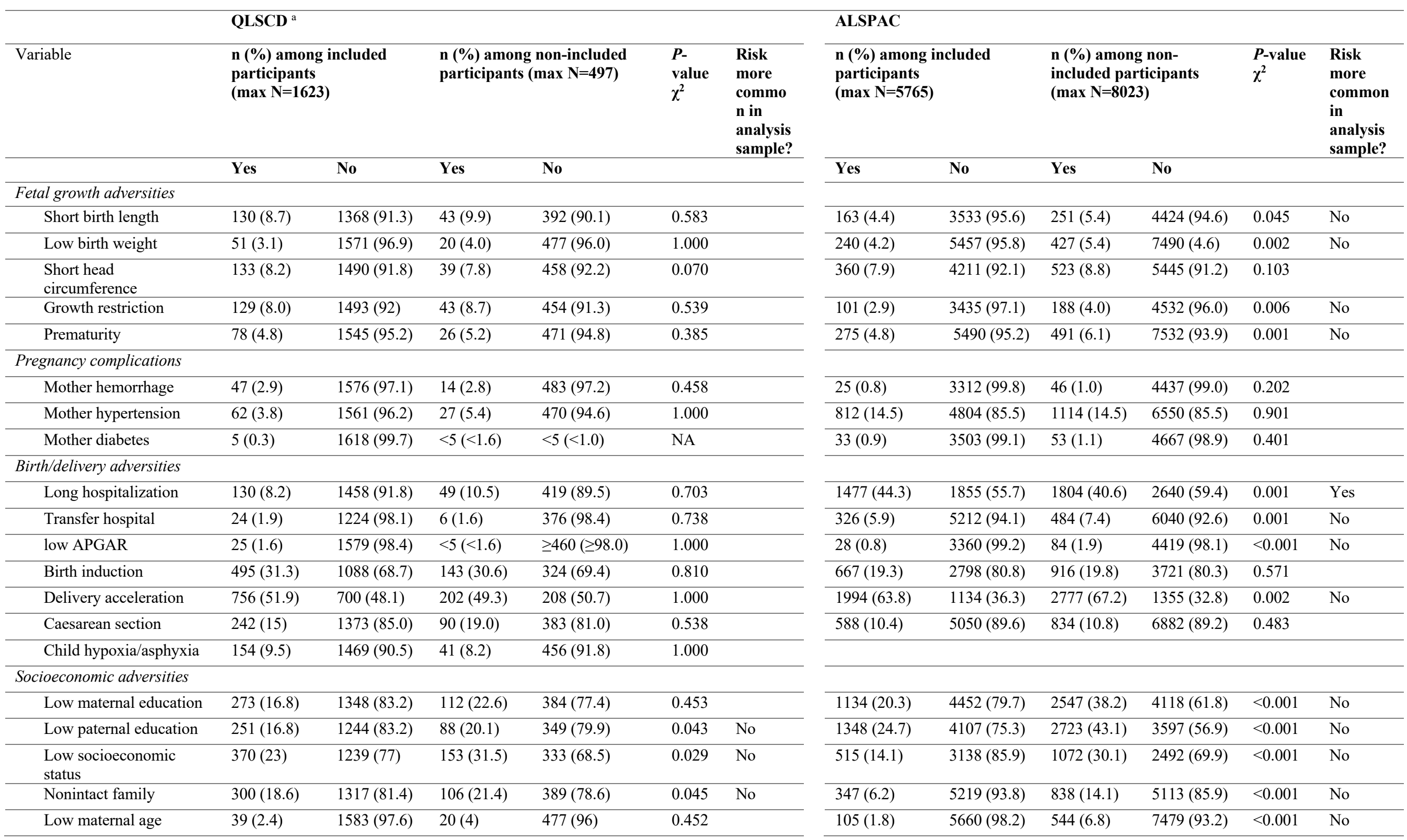




\begin{tabular}{|c|c|c|c|c|c|c|c|c|c|c|c|c|}
\hline Advanced paternal age & $444(29.5)$ & $1063(70.5)$ & $126(28.4)$ & $317(71.6)$ & 0.021 & Yes & $803(20.0)$ & $3214(80.0)$ & $581(15.5)$ & $3173(84.5)$ & $<0.001$ & Yes \\
\hline High birth order & $71(4.4)$ & $1552(95.6)$ & $86(17.3)$ & $411(82.7)$ & 0.945 & & $515(9.2)$ & $5086(90.8)$ & $704(10.5)$ & $6010(89.5)$ & 0.017 & No \\
\hline \multicolumn{13}{|l|}{ Exposures during pregnancy } \\
\hline Maternal smoking & $393(24.3)$ & $1221(75.7)$ & $140(28.2)$ & $356(71.8)$ & 0.012 & No & $1056(18.4)$ & $4671(81.6)$ & $2487(32.6)$ & $5138(67.4)$ & $<0.001$ & No \\
\hline Maternal alcohol use & $622(38.5)$ & $992(61.5)$ & $130(26.2)$ & $366(73.8)$ & 0.499 & & $1687(29.6)$ & $4012(70.4)$ & $3226(41.7)$ & $4513(58.3)$ & $<0.001$ & No \\
\hline Maternal drug use & $22(1.4)$ & $1592(98.6)$ & $8(1.6)$ & $488(98.4)$ & 0.566 & & $288(5.0)$ & $5450(95.0)$ & $437(5.7)$ & $7241(94.3)$ & 0.088 & \\
\hline Maternal medication use & $1026(63.6)$ & $586(36.4)$ & $288(58.1)$ & $208(41.9)$ & 0.538 & & $3732(66.2)$ & $1909(33.8)$ & $4736(65.5)$ & $2498(34.5)$ & 0.413 & \\
\hline \multicolumn{13}{|l|}{ Parental mental health } \\
\hline Maternal depression & $222(13.7)$ & $1395(86.3)$ & $96(19.4)$ & $400(80.6)$ & 0.156 & & $406(7.6)$ & $4957(92.4)$ & $562(9.9)$ & $5123(90.1)$ & $<0.001$ & No \\
\hline Paternal depression & $80(5.7)$ & $1315(94.3)$ & $28(7.5)$ & $347(92.5)$ & 0.935 & & $99(2.6)$ & $3730(97.4)$ & $107(3.4)$ & $3058(96.6)$ & 0.05 & No \\
\hline Maternal anxiety & & & & & & & $1354(25.3)$ & $4009(74.8)$ & $1679(29.5)$ & $4006(70.5)$ & $<0.001$ & No \\
\hline Paternal anxiety & & & & & & & $166(4.3)$ & $3705(95.7)$ & $157(4.9)$ & $3055(95.1)$ & 0.228 & \\
\hline $\begin{array}{l}\text { Maternal antisocial } \\
\text { behavior }\end{array}$ & $315(20.2)$ & $1248(79.8)$ & $88(19)$ & $374(81)$ & 0.835 & & & & & & & \\
\hline $\begin{array}{l}\text { Paternal antisocial } \\
\text { behavior }\end{array}$ & $326(23.4)$ & $1067(76.6)$ & $79(21.4)$ & $291(78.6)$ & 0.034 & Yes & & & & & & \\
\hline Child sex (female) & $845(52.1)$ & $778(47.9)$ & $195(39.2)$ & $302(60.8)$ & $\begin{array}{l}<0.00 \\
1\end{array}$ & Yes & $3356(58.2)$ & $2409(41.8)$ & $3311(41.3)$ & $4712(58.7)$ & $<0.001$ & Yes \\
\hline
\end{tabular}

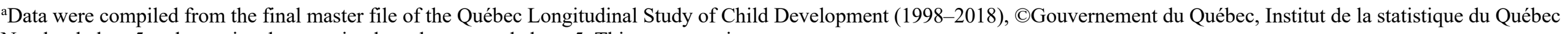
Number below 5 and associated proportion have been rounded at $<5$. This may contain zero. 
Table S2. Assessment of behavioral, emotional, interpersonal problems and cognitive skills in QLSCD and ALSPAC

\begin{tabular}{|c|c|c|}
\hline & QLSCD $^{\mathrm{a}}$ & ALSPAC \\
\hline Behavioral problems & $\begin{array}{l}\text { Assessment: Assessed with the Social } \\
\text { Behavioral Questionnaire. } \\
\text { E.g., "get into many fights", "physically } \\
\text { attack people" } \\
\text { Rating: teacher-report } \\
\text { Time points (child age, y): } 6,7,8,10,12 \\
\text { Number of items: } 9 \text { (3-point scale) } \\
\text { Alpha range: } 0.87-0.88\end{array}$ & $\begin{array}{l}\text { Assessment: Assessed with the Strengths and } \\
\text { Difficulties Questionnaires. } \\
\text { E.g., "Often fights with other children or bullies } \\
\text { them", "Picked on or bullied by other children" } \\
\text { Rating: teacher-report } \\
\text { Time points (child age, y): } 7 / 8,10 / 11 \\
\text { Number of items: } 5 \text { (3-point scale) } \\
\text { Alpha range: } 0.73-0.78\end{array}$ \\
\hline Hyperactivity/impulsivity & $\begin{array}{l}\text { Assessment: Assessed with the Social } \\
\text { Behavioral Questionnaire. } \\
\text { E.g., "can't sit still, restless", "cannot stop } \\
\text { fidgeting" } \\
\text { Rating: teacher-report } \\
\text { Time points (child age, y): } 6,7,8,10,12 \\
\text { Number of items: } 4 \text { (3-point scale) } \\
\text { Alpha range: } 0.82-0.84\end{array}$ & $\begin{array}{l}\text { Assessment: Assessed with the Strengths and } \\
\text { Difficulties Questionnaires } \\
\text { E.g., "Restless, overactive, cannot stay still for } \\
\text { long", "Fidgetiness, restlessness or overactivity" } \\
\text { Rating: teacher-report } \\
\text { Time points (child age, y): } 7 / 8,10 / 11 \\
\text { Number of items: } 5 \text { (3-point scale) } \\
\text { Alpha range: } 0.89-0.90\end{array}$ \\
\hline Emotional problems & $\begin{array}{l}\text { Assessment: Assessed with the Social } \\
\text { Behavioral Questionnaire. E.g., "not as } \\
\text { happy as other children", "too } \\
\text { fearful/anxious" } \\
\text { Rating: teacher-report } \\
\text { Time points (child age, y): } 6,7,8,10,12 \\
\text { Number of items: } 7 \text { (3-point scale) } \\
\text { Alpha range: } 0.79-0.81\end{array}$ & $\begin{array}{l}\text { Assessment: Assessed with the Strengths and } \\
\text { Difficulties Questionnaires } \\
\text { E.g., "Often unhappy, depressed or tearful", } \\
\text { "Many fears, easily scared" } \\
\text { Rating: teacher-report } \\
\text { Time points (child age, y): } 7 / 8,10 / 11 \\
\text { Number of items: } 5 \text { (3-point scale) } \\
\text { Alpha range: } 0.83-0.83\end{array}$ \\
\hline Peer victimization & $\begin{array}{l}\text { Assessment: Self-report victimization } \\
\text { scale (modified version) } \\
\text { Rating: self-report } \\
\text { Time points (child age, y): } 6,7,8,10,12 \\
\text { Number of items: } 7 \text { (3-point scale) } \\
\text { Alpha range: } 0.70-0.80\end{array}$ & $\begin{array}{l}\text { Assessment: Assessed with the Bullying and } \\
\text { Friendship Interview Schedule } \\
\text { Rating: self-report } \\
\text { Time points (child age, y): } 7 / 8,10 / 11 \\
\text { Number of items: } 5 \\
\text { Alpha range: } 0.59-0.61\end{array}$ \\
\hline Cognitive skills & $\begin{array}{l}\text { Assessment: Peabody Picture Vocabulary } \\
\text { Test } \\
\text { Rating: direct assessment performed by a } \\
\text { research professional } \\
\text { Time points (child age, y): } 4,7,10 \\
\text { Number of items: NA } \\
\text { Alpha range: NA }\end{array}$ & $\begin{array}{l}\text { Assessment: Wechsler Preschool \& Primary } \\
\text { Scale of Intelligence (full battery) and the } \\
\text { Wechsler Intelligence Scale for Children (short } \\
\text { form of the measure was employed where } \\
\text { alternate items were used for all subtests, with the } \\
\text { exception of the coding subtest which was } \\
\text { administered in its full form) } \\
\text { Rating: direct assessment performed by a } \\
\text { research professional } \\
\text { Time points (child age, y): } 4,8 \\
\text { Number of items: NA } \\
\text { Alpha range: NA }\end{array}$ \\
\hline
\end{tabular}

aData were compiled from the final master file of the Québec Longitudinal Study of Child Development (1998-2018),

(C) Gouvernement du Québec, Institut de la statistique du Québec 
Figure S1. Prevalence of suicide attempt by profile and sex in QLSCD $^{\mathrm{a}}$ and ALSPAC
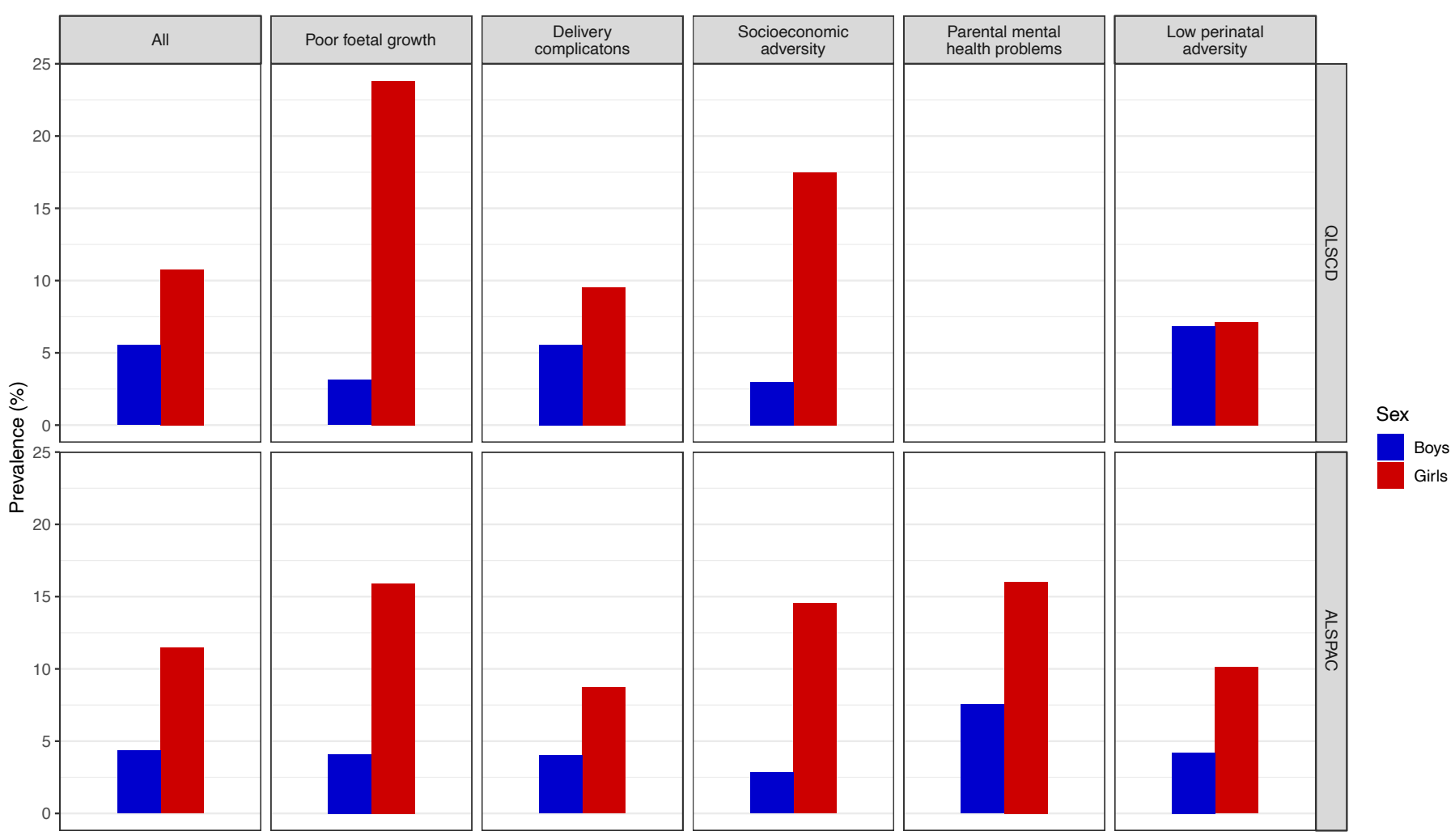

a'Data were compiled from the final master file of the Québec Longitudinal Study of Child Development (1998-2018), CGouvernement du Québec, Institut de la statistique du Québec 